University of Nebraska - Lincoln

DigitalCommons@University of Nebraska - Lincoln

$5-2010$

\title{
Glycopeptidome of a Heavily N-Glycosylated Cell Surface Glycoprotein of Dictyostelium Implicated in Cell Adhesion
}

\author{
Christa L. Feasley \\ University of Oklahoma Health Sciences Center \\ Jennifer M. Johnson \\ University of Oklahoma Health Sciences Center \\ Christopher M. West \\ University of Oklahoma Health Sciences Center, Cwest2@ouhsc.edu \\ Catherine P. Chia \\ University of Nebraska-Lincoln, cchia1@unl.edu
}

Follow this and additional works at: https://digitalcommons.unl.edu/bioscifacpub

Part of the Biochemistry Commons, Cell Biology Commons, and the Structural Biology Commons

Feasley, Christa L.; Johnson, Jennifer M.; West, Christopher M.; and Chia, Catherine P., "Glycopeptidome of a Heavily N-Glycosylated Cell Surface Glycoprotein of Dictyostelium Implicated in Cell Adhesion" (2010). Faculty Publications in the Biological Sciences. 124.

https://digitalcommons.unl.edu/bioscifacpub/124

This Article is brought to you for free and open access by the Papers in the Biological Sciences at DigitalCommons@University of Nebraska - Lincoln. It has been accepted for inclusion in Faculty Publications in the Biological Sciences by an authorized administrator of DigitalCommons@University of Nebraska - Lincoln. 


\title{
Glycopeptidome of a Heavily N-Glycosylated Cell Surface Glycoprotein of Dictyostelium Implicated in Cell Adhesion
}

\author{
Christa L. Feasley, ${ }^{1}$ Jennifer M. Johnson, ${ }^{1}$ Christopher M. West, ${ }^{1}$ and Catherine P. Chia ${ }^{2}$ \\ 1. Department of Biochemistry \& Molecular Biology and the Oklahoma Center for Medical Glycobiology, \\ University of Oklahoma Health Sciences Center, Oklahoma City, Oklahoma 73104 \\ 2. School of Biological Sciences, University of Nebraska-Lincoln, Lincoln, Nebraska 68588-0118 \\ Corresponding author - Chris West, Oklahoma Center for Medical Glycobiology, Department of Biochemistry and Molecular Biology, \\ OUHSC, 975 NE 10th St., BRC 417, Oklahoma City, OK, 73104; tel 405-271-4147, email Cwest2@ouhsc.edu
}

Authors C. M. West and C. P. Chia contributed equally to the project.

\begin{abstract}
Genetic analysis has implicated the cell surface glycoprotein gp130 in cell interactions of the social amoeba Dictyostelium, and information about the utilization of the $18 \mathrm{~N}$-glycosylation sequons present in gp130 is needed to identify critical molecular determinants of its activity. Various glycomics strategies, including mass spectrometry of native and derivatized glycans, monosaccharide analysis, exoglycosidase digestion, and antibody binding, were applied to characterize a nonanchored version secreted from Dictyostelium. s-gp130 is modified by a predominant Man ${ }_{8} \mathrm{GlCNAc}_{4}$ species containing bisecting and intersecting GlcNAc residues and additional high-mannose N-glycans substituted with sulfate, methyl-phosphate, and/or core a3-fucose. Site mapping confirmed the occupancy of 15 sequons, some variably, and glycopeptide analysis confirmed 14 sites and revealed extensive heterogeneity at most sites. Glycopeptide glycoforms ranged from Man 6 to $\mathrm{Man}_{9}, \mathrm{GlcNAc}_{0-2}$ (peripheral), Fuc ${ }_{0-2}$ (including core $\mathrm{a} 3$ and peripheral), $\left(\mathrm{SO}_{4}\right)_{0-1}$, and $\left(\mathrm{MePO}_{4}\right)_{0-1}$, which represented elements of virtually the entire known cellular N-glycome as inferred from prior metabolic labeling and mass spectrometry studies. gp130, and a family of 14 related predicted glycoproteins whose polypeptide sequences are rapidly diverging in the Dictyostelium lineage, may contribute a functionally important shroud of high-mannose N-glycans at the interface of the amoebae with each other, their predators and prey, and the soil environment.
\end{abstract}

Keywords: N-glycan, Dictyostelium, mass spectrometry, glycobiology, glycopeptidome, gp130

\section{Introduction}

Dictyostelium discoideum is a social amoeba that normally resides in the soil on a diet of bacteria. gp130 is a surface-exposed plasma membrane glycoprotein that is likely equivalent to gp126, which was originally postulated to be a phagocytosis receptor and a component of contact site B, a cell-cell adhesion system. ${ }^{1,2}$ Antibody-induced depletion of gp130 from cells labeled with membrane-impermeant reagents supported a role in gram-negative bacterial phagocytosis, ${ }^{1-3}$ but gp130null cells were found to be phagocytosis competent, suggesting that gp130 is not required. ${ }^{4}$ However, gp130-null cells exhibited a greater rate of macropinocytosis, an alternative feeding strategy available in the axenic mutant background of most laboratory strains. In addition, gp130-null cells exhibited enhanced cell-cell cohesion and readily formed small aggregates in axenic media or after brief starvation, suggesting decreased repulsion exhibited by wild type cells. Levels of gp130 and its transcript declined as normal cells underwent starvation-induced aggregation and development, ${ }^{4}$ consistent with a contact inhibition role during growth. gp130 is related to a family of 4 gp138 cell surface glycoproteins implicated in sex- ual cell fusion ${ }^{5-7}$ and cell-cell interactions ${ }^{8,9}$ and 10 other predicted proteins (see below), suggesting an even larger role for this class of proteins in cell-cell and cell-environment transactions.

Gene sequencing predicted that gp130 has an unprocessed $M_{r}$ of 81666 , but antibodies against recombinant gp130 identified a plasma membrane and cell surface associated protein with an apparent $M_{\mathrm{r}}$ of 130000 based on SDS-PAGE. The predicted coding sequence contains $18 \mathrm{~N}$-glycosylation sequons, a sequence motif (Asn-X-Ser/Thr, where $X \neq$ Pro) that is a candidate for N-glycosylation. Biochemical analyses showed that gp130 binds the lectin Concanavalin A (Con A), suggesting that the apparent $M_{\mathrm{r}}$ discrepancy may be explained by extensive N-glycosylation. Sequence analyses also predict that gp130 is directed to the secretory pathway by a cleavable signal peptide, and contains a cleavable C-terminal signal that directs the attachment for a GPI-anchor. These signals are expected to expose the entire coding region to glycosylation processing pathways and present gp130 at the cell surface. Although the gp130 polypeptide possesses several amino acid repeat motifs, sequence comparisons have not identified any clear homologies to aid in dissecting the function of gp130. 
In part on the basis of the projected number of glycans and their likely presentation on the exterior of gp130, we propose that the glycans themselves contribute to its suspected roles in cell interactions and endocytosis. This hypothesis is consistent with the thick glycocalyx present at the cell surface of the amoebae, ${ }^{10}$ poor conservation of the gp130-polypeptide sequence in related species as reported here, and evidence for extensive N-glycosylation differences among different social amoebae. ${ }^{11}$ Previous studies of $D$. discoideum have implicated glycoproteins and oligosaccharide moieties in cell adhesion, ${ }^{12-16}$ phagocytosis ${ }^{17}$ and sexual development. ${ }^{18-20}$ Classical methods ${ }^{21}$ and a recent mass spectrometry-based study ${ }^{22}$ describe major features of the $D$. discoideum $\mathrm{N}$-glycome, but it is not known which are presented at the cell surface. Here we apply a mass spectrometry-based approach to analyze the Nglycans on a secreted recombinant version of gp130. Although the protein expresses a predominant high-mannose N-glycan with bisecting and intersecting GlcNAc-residues, its N-glycans are extensively microheterogeneous and include sulfated and phosphorylated N-glycans described by classical premass spectrometry approaches. ${ }^{21}$ Analysis of the glycopeptidome confirmed the observations and mapped the distribution of glycoforms over 15 of the 18 candidate glycosylation sites. The glycan map will inform future strategies to investigate the role of gp130 glycans in cell surface functions.

\section{Experimental Procedures}

Cell Strains and Cell Culture. Strains HL250 $(\operatorname{modC})$ and HW11 (modB), derived from Ax3, DBS0235414 (gp130-null) and CC11 (s-gp130 producer), derived from DH1, and Ax2, were grown axenically in shaking HL-5 culture medium at $22{ }^{\circ} \mathrm{C} .{ }^{23}$

Cloning of gp130 cDNA. gp130 cDNA was generated from an oligo dT-primed reverse transcriptase reaction using total RNA isolated from growth-phase strain Ax2 with TRIZOL Reagent (Invitrogen), followed by PCR amplification using Taq polymerase and gene specific primers 5'-AAATGAAAAAAAATTATTTATTTTTAT and 5'-TCACTTTACCAAAATAATGTAA. The product was cloned into pSTBlue-1 (Novagen), and its translated sequence (GenBank AAK69771) was identical to the splice model at Dictybase.org (DDB0214937).

s-gp130 Expression. The coding region for the predicted polypeptide after cleavage of the $\mathrm{N}$ - and C-terminal signal peptides was amplified from pSTBlue-gp130 using CD11F, 5'-AGTGGATCCGGACAAACAAAACCACTTCCATCAGATCAAATGGAA, and CD11R, 5'-AGTGGATCCATCATGACCATTTTCTTCAGAGGATGT. The BamH1-digested gelpurified PCR product was directionally cloned into the BglII site of $\mathrm{pVS}^{23}$ and $\mathrm{pVS}-\mathrm{CD} 11$ was electroporated into the gp130-null strain DBS0235414. ${ }^{4}$ Producers were selected in 20 $\mu \mathrm{g} / \mathrm{mL}$ G418 and clones were screened using silver-stained SDS-PAGE gels. Clone CC11 was used for the present study.

s-gp130 Purification. Strain CC11 was grown in HL-5 to stationary phase. The culture supernatant was obtained by centrifugation at $300 \times g$ for $10 \mathrm{~min}$, brought to $50 \%(\mathrm{w} / \mathrm{v})$ $\left(\mathrm{NH}_{4}\right)_{2} \mathrm{SO}_{4}$ at $4{ }^{\circ} \mathrm{C}$ and centrifuged at $10000 \times \mathrm{g}$ for $20 \mathrm{~min}$. The pellet was resuspended in $20 \mathrm{mM} \mathrm{Na}$ phosphate, $\mathrm{pH}$ 6.8, and dialyzed against wash buffer $(500 \mathrm{mM} \mathrm{NaCl}, 20 \mathrm{mM}$ Tris- $\mathrm{HCl}$, $\mathrm{pH}$ 7.4). The sample was clarified at $10000 \times \mathrm{g}$ for $10 \mathrm{~min}$ and applied to a column of Con A-agarose (Sigma, St. Louis, MO) equilibrated in wash buffer at $4{ }^{\circ} \mathrm{C}$, washed, and eluted with $0.2 \mathrm{M}$ a-methyl-mannoside in wash buffer at $22{ }^{\circ} \mathrm{C}$. The eluate was dialyzed at $4{ }^{\circ} \mathrm{C}$ against $20 \mathrm{mM}$ sodium phosphate,
pH 6.8, and clarified again by centrifugation. The sample was adjusted to $50 \%(\mathrm{w} / \mathrm{v})\left(\mathrm{NH}_{4}\right)_{2} \mathrm{SO}_{4}$ and loaded onto a phenylSepharose High-performance Hi-trap column (low sub; GE Healthcare) equilibrated in $50 \%(\mathrm{w} / \mathrm{v})\left(\mathrm{NH}_{4}\right)_{2} \mathrm{SO}_{4}$ in $100 \mathrm{mM}$ Tris- $\mathrm{HCl}, \mathrm{pH} 7.5$, at $22{ }^{\circ} \mathrm{C}$. The column was eluted with a descending step gradient of $\left(\mathrm{NH}_{4}\right)_{2} \mathrm{SO}_{4}$. The 30-25\% $\left(\mathrm{NH}_{4}\right)_{2} \mathrm{SO}_{4}$ fractions, which contained gp130 based on Western blotting, were dialyzed against $100 \mathrm{mM}$ Tris- $\mathrm{HCl}, \mathrm{pH} 7.5$, diluted 5-fold, applied to a Q-Sepharose (GE Healthcare) column equilibrated in $20 \mathrm{mM}$ Tris- $\mathrm{HCl}, \mathrm{pH} 7.5$, and eluted in an ascending step gradient of $\mathrm{KCl}$ in the same buffer. The $0.2-0.3$ $\mathrm{M} \mathrm{KCl}$ fractions were concentrated in a Centricon-100 centrifugal concentrator (Millipore), and applied to a Superdex $200(1.6 \times 60 \mathrm{~cm}$, GE Healthcare) column equilibrated in 20 $\mathrm{mM} \mathrm{NH} \mathrm{HCO}_{3}, \mathrm{pH}$ 7.8. s-gp130 eluted as a single symmetrical peak, at a final yield of $80 \mu \mathrm{g}$ from $1750 \mathrm{~mL}$ of culture media. s-gp130 behaved as a single population during each step of purification. Sugar composition and glycomic profiles were confirmed in independent preparations.

Butanol-Extraction of GPI-anchored Proteins and Purification of gp130. The particulate fraction (P100) of strain Ax3 was isolated by centrifugation of filter-lysed cells at $100000 \times$ $g$ for $1 \mathrm{~h},{ }^{24}$ and resuspended at $2.5 \mathrm{mg}$ protein $/ \mathrm{mL}$ in $10 \mathrm{mM}$ sodium citrate $(\mathrm{pH} 5.5)$ at $4{ }^{\circ} \mathrm{C}$. Three-fourths volume of cold $n$-butanol was added to the resuspended membranes and agitated for $5 \mathrm{~min}$ at $4{ }^{\circ} \mathrm{C} .{ }^{25}$ The resulting solution was centrifuged $10000 \times \mathrm{g}$ for $30 \mathrm{~min}$ to form three layers. The butanol saturated aqueous lower layer was applied at $4{ }^{\circ} \mathrm{C}$ at $2.5 \mathrm{~mL} /$ min to a 5-mL High Trap Sepharose Q column (GE Healthcare) pre-equilibrated in load buffer ( $20 \mathrm{mM}$ Tris- $\mathrm{HCl}, \mathrm{pH} 7.5)$ and eluted with an ascending gradient to $1 \mathrm{M} \mathrm{NaCl}$ in load buffer containing $0.2 \%$ octyl-glucoside. gp130 eluted as a single peak at $\sim 450 \mathrm{mM} \mathrm{NaCl}$ based on Western blot analysis with rabbit anti-gp130.

SDS-PAGE and Western Blotting. Proteins were electrophoresed on SDS-PAGE gels, and either semi-dry transferred to $0.45 \mu \mathrm{m}$ pore size nitrocellulose (Bio-Rad), ${ }^{24}, 26$ or silver-stained as described ${ }^{27}$ except that $0.1 \%$ silver nitrate was supplemented with $0.08 \%$ formalin. gp130 and s-gp130 were probed with rabbit anti-gp130 $\mathrm{Ab}^{4}$ followed by detection with Alexa 680-conjugated antirabbit IgG (Invitrogen). myc-tagged s-gp130 was probed with mAb 9E10 followed by Alexa 680-conjugated antimouse $\mathrm{Ab}$ (Invitrogen). To detect Fuc, s-gp130 (2 $\mathrm{\mu g})$, total membranes of axenically grown or 16 h-starved Ax3 cells (30 $\mu \mathrm{g}$ protein), and the $n$-butanol extract $(10 \mu \mathrm{g}$ protein), were subjected to SDS-PAGE and Western blotted with a core a3-linked fucose specific antibody, prepared from rabbit anti-Horseradish peroxidase (HRP) (Jackson ImmunoResearch) by affinity purification against HRP, as described. ${ }^{28,} 29$

Monosaccharide Composition Analysis by HPAEC-PAD ${ }^{30}$. Purified s-gp130 (10 $\mu \mathrm{g})$ and a reagent blank were vacuumdried in 1.5-mL conical polypropylene tubes (Eppendorf) and incubated in $200 \mu \mathrm{L}$ of $4 \mathrm{M}$ TFA at $100{ }^{\circ} \mathrm{C}$ for $4 \mathrm{~h}$. TFA was removed by centrifugal evaporation, and the sample was resuspended in water and analyzed by HPAEC using a Carbo-Pac PA-1 (Dionex) column on a Dionex DX-600. The column was eluted isocratically with $14 \mathrm{mM} \mathrm{NaOH}$ for $20 \mathrm{~min}$ and then with an ascending gradient of sodium acetate $(0-500 \mathrm{mM})$ in $100 \mathrm{mM}$ $\mathrm{NaOH}$ for $50 \mathrm{~min}$. Monosaccharides, observed by pulsed amperometric detection (PAD), were identified based on elution time, and quantitated by comparison of PAD values to a standard curve for each monosaccharide (Dionex). Values for glucose, which were similar to the value in the reagent blank, were assumed to reflect environmental contamination. 
Amino Acid Analysis. Purified s-gp130 ( 40 $\mu \mathrm{g})$ was supplemented with beta-thienyl alanine (4 nmol), dried, and incubated in $6 \mathrm{~N} \mathrm{HCl}$ in sealed evacuated tubes for $24 \mathrm{~h}$ at 110 ${ }^{\circ} \mathrm{C}$. Amino acids were resolved by cation exchange chromatography and detected by online post column derivatization with ninhydrin in the OUHSC Proteomics facility. Total protein concentration was extrapolated from the average of values, corrected by molar ratios, for the stable amino acids.

Protease Digestions. Ten micrograms of purified s-gp130 was brought to $6 \mathrm{M}$ urea in $25 \mathrm{mM} \mathrm{NH}_{4} \mathrm{HCO}_{3}$ buffer (pH 7.8), $10 \mathrm{mM}$ dithiothreitol, and heated at $60^{\circ} \mathrm{C}$ for $30 \mathrm{~min}$. The sample was alkylated by the addition of iodoacetamide to a concentration of $30 \mathrm{mM}$ and incubated for $30 \mathrm{~min}$ at $22^{\circ} \mathrm{C}$, followed by the addition of dithiothreitol to a final concentration of $40 \mathrm{mM}$. After further incubation for $30 \mathrm{~min}$, the sample was diluted 8-fold with $25 \mathrm{mM} \mathrm{NH}_{4} \mathrm{HCO}_{3}$ (pH 7.8). Alkylated s-gp130 was treated with sequencing grade trypsin (1:50 enzyme:substrate) (Promega, Madison, WI) at $37^{\circ} \mathrm{C}$ for $18 \mathrm{~h}$. Half of the sample was subsequently treated with chymotrypsin (Sigma, St. Louis, $\mathrm{MO}$; 1:50 enzyme to substrate ratio) at $37^{\circ} \mathrm{C}$ for $18 \mathrm{~h}$. Pepsin (Amresco, Solon, $\mathrm{OH}$ ) digestion was conducted in $0.5 \%$ formic acid at 1:50 enzyme:substrate at $37^{\circ} \mathrm{C}$ for $4 \mathrm{~h}$.

Enzymatic Deglycosylation. For N-glycan release from protein, alkylated s-gp130 was diluted in glycoprotein denaturation buffer containing SDS (New England Biolabs), boiled for $10 \mathrm{~min}$, diluted with G7 reaction buffer containing $1 \% \mathrm{NP} 40$, and treated with $50 \mathrm{U}$ PNGase $\mathrm{F} / \mu \mathrm{g}$ protein for $18 \mathrm{~h}$ at $37^{\circ} \mathrm{C}$. Alternatively, alkylated s-gp130 was diluted to $0.8 \mathrm{M}$ urea with $25 \mathrm{mM} \mathrm{NH}_{4} \mathrm{HCO}_{3}(\mathrm{pH} \mathrm{7.8)}$, and treated with PNGase F as above. Partially purified gp130 was concentrated and buffer exchanged to $50 \mathrm{mM} \mathrm{Na}$ citrate ( $\mathrm{pH} 5.5), 0.25 \%$ SDS, using a Microcon 100 centrifugal concentrator (Amicon), heated at $60{ }^{\circ} \mathrm{C}$ for $15 \mathrm{~min}$, adjusted to $1 \%$ NP40, 0.125\% SDS, and treated with $500 \mathrm{U}$ Endoglycosidase $\mathrm{H}_{\mathrm{f}}\left(\right.$ Endo $\mathrm{H}_{\mathrm{f}}, 500 \mathrm{U}$, NEB) $/ 20 \mu \mathrm{L}$ reaction at $37^{\circ} \mathrm{C}$ for $18 \mathrm{~h}$.

For release from peptides, tryptic and/or chymotryptic peptides were adsorbed to a pre-equilibrated $\left(\mathrm{MeOH}\right.$ to $\mathrm{H}_{2} \mathrm{O}$ to $50 \% \mathrm{ACN}, 0.1 \%$ TFA in $\mathrm{H}_{2} \mathrm{O}$ to $0.1 \%$ TFA in $\mathrm{H}_{2} \mathrm{O}$ ) SepPak $\mathrm{C}_{18}$ cartridge (Waters) and eluted stepwise with $50 \% \mathrm{ACN}$, $0.1 \%$ TFA in water, and $80 \% \mathrm{ACN}, 0.1 \%$ TFA in water, dried in vacuo, resuspended in PNGase F buffer, and digested as above. For PNGase A digestion, peptic peptides were dried in vacuo and resuspended in $50 \mathrm{mM}$ citrate/ $\mathrm{Na}$ phosphate buffer $(\mathrm{pH}$ 5.0) and treated with $50 \mu \mathrm{U}$ PNGase A (Roche) $/ 25 \mu \mathrm{L}$ reaction for $18 \mathrm{~h}$ at $37^{\circ} \mathrm{C}$. N-glycans were collected as the flow-through fraction from a pre-equilibrated (see above) SepPak $\mathrm{C}_{18}$ cartridge and applied to a pre-equilibrated Carbograph cartridge (Grace Davison, Deerfield, IL), and washed extensively with water. N-glycans were eluted with $50 \%$ ACN, $0.1 \%$ TFA in water. For Endo $\mathrm{H}_{\mathrm{f}}$ digestion, tryptic peptides were dried and resuspended in $50 \mathrm{mM}$ Na citrate buffer ( $\mathrm{pH}$ 5.5) and treated with $500 \mathrm{U}$ Endo $\mathrm{H}_{\mathrm{f}} / 20 \mu \mathrm{L}$ reaction volume for $18 \mathrm{~h}$ at $37^{\circ} \mathrm{C}$.

Affinity Selection of Glycopeptides. Glycopeptides from proteolytic digests were enriched by hydrophilic interaction chromatography or by lectin Concanavalin A (Con A) selection. For the former, polyHYDROXYETHYL A TopTips (PolyLC, Columbia, MD) were pre-equilibrated with loading buffer $\left(80 \% \mathrm{ACN}, 0.5 \%\right.$ formic acid, $\left.19.5 \% \mathrm{H}_{2} \mathrm{O}\right)$. Lyophilized, digested s-gp130 peptides $(10 \mu \mathrm{L})$ were resuspended in loading buffer and applied. Unbound peptides were washed from the microcolumn with 5 column volumes of loading buffer. Glycopeptides were eluted with three column volumes of $0.5 \%$ formic acid in $\mathrm{H}_{2} \mathrm{O}$ and dried in vacuo. For Con A affinity selection, glycopeptides were applied to a SepPak $\mathrm{C}_{18}$ car- tridge, eluted and dried as above, resuspended in binding buffer (10 mM HEPES-NaOH, pH 7.5, $1 \mathrm{mM} \mathrm{CaCl}, 1 \mathrm{mM} \mathrm{MnCl}$ ), and incubated with $200 \mu \mathrm{L}$ of Con A agarose beads $(10 \mathrm{mg} /$ $\mathrm{mL}$ Con $\mathrm{A}$, Vector Laboratories) for $1 \mathrm{~h}$ at $22^{\circ} \mathrm{C}$ with rocking. The slurry was transferred to a Bio-Rad Econocolumn, and nonglycosylated peptides were removed by the addition of 10 bed volumes of binding buffer. Glycopeptides were eluted using 3 bed volumes of $0.2 \mathrm{M}$ a-methyl mannoside in binding buffer and desalted using a $\mathrm{C}_{18}$ SepPak.

Exoglycosidase Digestion. On target exoglycosidase digestions of s-gp130 N-glycans were adapted from other protocols. ${ }^{31-33}$ Briefly, purified 2AB-labeled glycans in 50\% methanol were spotted directly onto polished steel MALDI target plates with an equal volume of $10 \mathrm{mg} / \mathrm{mL}$ 6-aza-2-thiothymine in water matrix solution. Spots were dried under vacuum and resuspended in $1 \mu \mathrm{L}$ of $50 \mathrm{mM} \mathrm{NH}_{4} \mathrm{Ac}(\mathrm{pH} 5.0)$ at $10 \mathrm{U} / \mathrm{ml}$ jack bean $\beta$-hexosaminidase or a-mannosidase (Prozyme, Hayward, CA). The plates were incubated at $37^{\circ} \mathrm{C}$ in a humidified box for 2,4 , or $24 \mathrm{~h}$. Similar results were obtained with reactions conducted in microtubes in the absence of matrix (not shown).

Reductive Amination of N-Glycans. ${ }^{34}$ Purified PNGase Freleased glycans from s-gp130 were dried in vacuo in a $1.5 \mathrm{~mL}$ microcentrifuge tube and resuspended in $10 \mu \mathrm{L}$ of $0.4 \mathrm{M} 2 \mathrm{AB}$ in DMSO/glacial acetic acid (7:3). After $30 \mathrm{~min}$ incubation at $80^{\circ} \mathrm{C}, 10 \mu \mathrm{L}$ of $2 \mathrm{M}$ sodium cyanoborohydride in the same solvent was added and incubation continued for an additional 90 min. Reactions were spotted directly onto Whatman 3MM paper and dried. Paper chromatograms were developed using $n$ butanol:ethanol:water (4:1:1) and air-dried. Spot origins were excised and labeled glycans eluted using $400 \mu \mathrm{L} \mathrm{H}_{2} \mathrm{O}$.

Reversed-Phase HPLC of 2AB-Labeled Glycans. 2ABlabeled glycans (10-20 pmol) were eluted isocratically in 3\% $\mathrm{ACN}, 0.5 \%$ acetic acid in water from a $\mathrm{C}_{18} 4.6 \times 250 \mathrm{~mm}$ column (Vydac Peptide/Protein $\mathrm{C}_{18}$ 218TP54) at $0.2 \mathrm{~mL} / \mathrm{min}$. Fractions were collected every minute, dried in vacuo, and resuspended in $5 \mu \mathrm{L}$ of $50 \%$ methanol/50\% water for MALDITOF-MS analysis.

Permethylation of Glycans. Spin column permethylation was performed as described. ${ }^{35}$ As an alternative to liquidliquid extraction, the permethylation reaction was subject to solid-state extraction on a C18 cartridge, ${ }^{36}$ which was eluted stepwise with $5,15,35,50$, and $80 \%$ ACN with $0.1 \%$ TFA in $\mathrm{H}_{2} \mathrm{O}$. Samples were dried and resuspended in $10 \mu \mathrm{L}$ of $50 \%$ methanol $/ 50 \% \mathrm{H}_{2} \mathrm{O}$ for MS analysis. Similar results were obtained for either method (not shown).

O-Glycan Analysis. A pepsin/PNGase A digest was subjected to conventional reductive $\beta$-elimination ${ }^{37}$ and spin column permethylation, ${ }^{38}$ and analyzed by MALDI-TOF-MS. ${ }^{39}$ Alternatively, nonreductive, $\mathrm{NH}_{3}$-based $\beta$-elimination of glycans ${ }^{40}$ from PNGase F-treated tryptic peptides was followed by $2 \mathrm{AB}$ labeling ${ }^{34}$ and analysis by MALDI-TOF-MS and RPHPLC chromatography. ${ }^{41}$

MALDI-TOF/TOF-MS. MALDI-TOF-MS analyses of peptide and glycans were performed on an Ultraflex II (Bruker Daltonics, Billerica, MA) with a LIFT apparatus for TOF/TOF experiments. Samples were spotted with an equal volume of 2,5-dihydroxybenzoic acid matrix for glycans $(20 \mathrm{mg} / \mathrm{mL}$ in $50 \% \mathrm{ACN}, 0.1 \%$ TFA in $\mathrm{H}_{2} \mathrm{O}$ ) or a-cyano-4-hydrocinnaminic acid for glycopeptides $(10 \mathrm{mg} / \mathrm{mL}$ in $50 \% \mathrm{ACN}, 0.1 \% \mathrm{TFA}$ in $\mathrm{H}_{2} \mathrm{O}$ ) and vacuum-dried. Glycans were also routinely screened using utilizing 2', 4',6'-trihydroxyacetophenone monohydrate as an alternative matrix. A dextrin ladder was used as an external mass calibrant $\left(M_{\mathrm{r}} 500-3000, \mathrm{~V}\right.$-laboratories, Covington, 
Figure 1. Sequences of gp130 and s-gp130, and summary of glycosylation site occupancy. The gp130 sequence is shown in black. Recombinant gp130 (s-gp130) is identical except at the termini, where black italicized gp130 sequences are replaced by the sequences below in purple. These changes are predicted to extend the N-terminus with a DRSG tetrapeptide after signal sequence processing, and replace the putative C-terminal GPI anchor processing sequence with a c-myc epitope tag. These changes, and $85 \%$ of the predicted s-gp 130 sequence were confirmed by the MS studies described below (amino acids not detected are in gray). Predicted N-glycosylation sites (N-sequons) are underlined/bolded and colored according to experimental data indicating full occupancy (green), partial occupancy (blue), or unoccupied (black), as summarized in Table 4 below.

LA) for glycan samples and a seven-component peptide mixture (Bruker Daltonics) was used for glycopeptides. Mass accuracy was typically $<50$ ppm for glycans and $<100$ ppm for glycopeptides. The instrument was operated in reflectron positive ion mode with an accelerating voltage of $25 \mathrm{kV}$, except as indicated. MALDI-TOF/TOF spectra were acquired at 66 $\mathrm{Hz}$ laser frequency and 1000-5000 individual spectra were summed; precursor ions were accelerated to $8 \mathrm{kV}$ and selected by a timed ion gate. Fragment ions generated by laser-induced dissociation were subsequently accelerated at $19 \mathrm{kV}$ by the LIFT apparatus. High energy CID was performed using Ar as the collision gas.

nanoLC-MS/MS. Two $\mu \mathrm{g}$ of total trypsin digest was loaded onto a $\mathrm{C}_{18}$ column (Acclaim PepMap100 $\mathrm{C}_{18}, 3 \mu \mathrm{m}, 100$ A pore) pre-equilibrated in Buffer A, and peptides were eluted with a linear gradient of $10-70 \%$ buffer B in 40 min (Buffer A: $2 \%$ ACN, $0.09 \%$ formic acid, $0.01 \%$ TFA in $\mathrm{H}_{2} \mathrm{O}$; Buffer $\mathrm{B}: 95 \%$ ACN, $0.09 \%$ formic acid, $0.0085 \%$ TFA in $\mathrm{H}_{2} \mathrm{O}$ ). The nanoLC (Ultimate 3000 nanoLC system; Dionex, Sunnyvale CA) was directly infused into a QSTAR Elite (Applied Biosystems) (ion spray voltage: $2500 \mathrm{~V}$, ion source gas: 22 psi, curtain gas: 20 psi), such that peak width was $~ 30 \mathrm{~s}$. The QSTAR elite was externally calibrated daily with a four peptide mixture (range 498-1063 m/z). Data-dependent MS/MS fragmentation of precursor ions was performed on the top 3 ions with a $250 \mathrm{~s}$ exclusion time (survey: $620-3300 \mathrm{~m} / \mathrm{z}$ with charge 2 to 5 if signal exceeds 10 cts). Mass accuracies, typically $<250$ ppm for glycopeptides, are listed in Table 5.

Alternatively, 2 pmol of a pepsin or trypsin-chymotrypsin digest (with or without Con A enrichment) was introduced into a $\mathrm{C}_{18}$ column (self-packed into New Objective PicoTip) mounted on a splitless Eskigent nanoLC 1D (Dublin, CA), preequilibrated with $2 \%$ buffer B (Buffer A: $0.1 \%$ formic acid in $\mathrm{H}_{2} \mathrm{O}$ and Buffer B: $2 \% \mathrm{H}_{2} \mathrm{O}, 0.1 \%$ formic acid in ACN). Pep- tides were eluted with a $2-70 \%$ linear gradient of buffer B over 45 min and directly infused into a LTQ XL (Thermo-Electron, Waltham, MA). A survey scan of the range from 300-1800 m/z was performed for each time interval, followed by data-dependent MS/MS fragmentation on the top three ions with a $120 \mathrm{~s}$ exclusion time. Mass accuracy was typically <500 ppm for glycopeptides.

\section{Results}

s-gp130 Expression and Purification. The gp130 coding sequence contains a predicted N-terminal cleavable signal peptide and a C-terminal cleavable signal for the addition of a GPI-anchor. To produce sufficient gp130 for glycosylation analysis, the coding sequence of the predicted processed polypeptide was cloned into a standard expression vector for secretory proteins, pVS. ${ }^{23}$ The resulting s-gp130 protein consisted of an N-terminal cleavable signal peptide derived from $c e l A$, the predicted processed gp130 polypeptide, and a C-terminal c-myc epitope tag that replaced the putative GPI-anchor signal. Modifications to the original sequence are indicated in Figure 1.

When expressed in gp130-null cells, s-gp130 was readily detected in the growth medium by SDS-PAGE and purified as a single protein population over columns of Concanavalin A, phenyl Sepharose, and Q-Sepharose (see Experimental Procedures). s-gp130 eluted as a symmetrical peak during the final gel filtration purification step (Figure 2A), and SDS-PAGE confirmed that the great majority of protein migrated at the position of s-gp130 (Figure 2B). Probing of a Western blot with antigp130 antiserum (Figure 2C, lane U) identified the same profile of major and minor bands, which confirmed the identity of the major band, and indicated that the minor bands in the silver stained gel represented electrophoretic variants of s-gp130. The purity of the preparation was confirmed by the absence of non- 

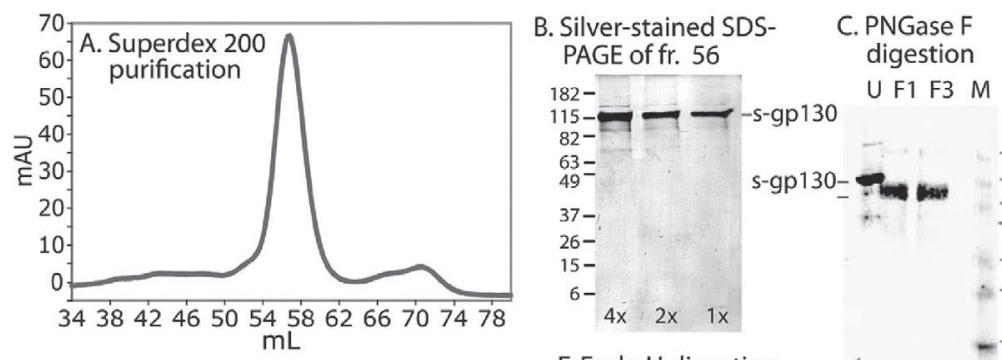

D. anti- $\alpha 3$ Fuc $A b$

E. s-gp130, gp130 in glycosylation mutants
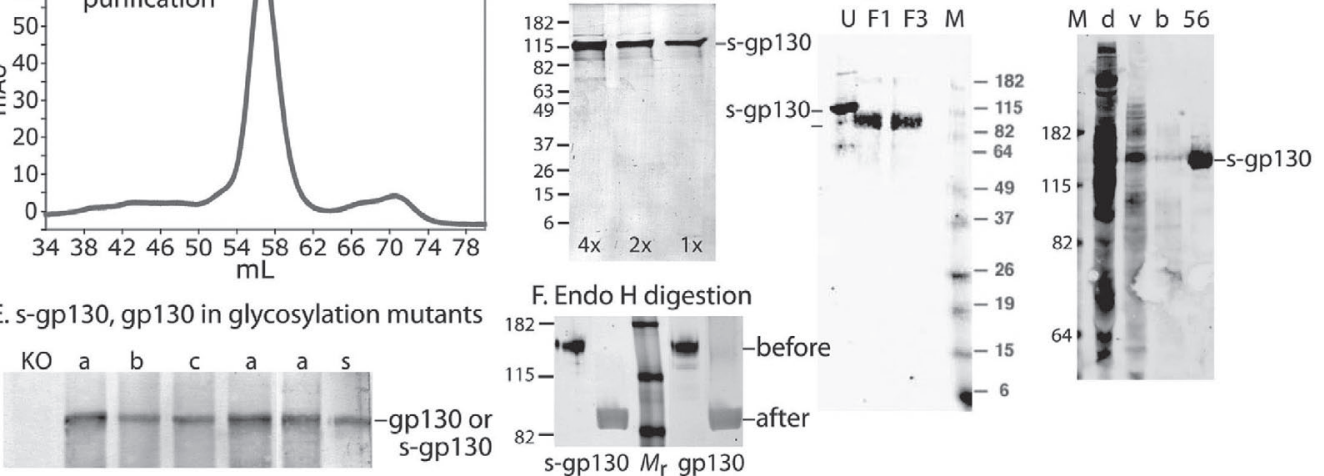

Figure 2. SDS-PAGE analysis of s-gp130 glycosylation. (A) $\mathrm{A}_{280}$ trace from final gel filtration step of the purification. (B) Silver-stained SDSPAGE (7-20\% acrylamide for panels B-D) analysis of fraction 56 shown in panel A. Lanes represent 2-fold serial dilutions. (C) Western blot of untreated s-gp130 (U), or s-gp130 treated with 1 or $3 \mu \mathrm{L}$ of PNGase F (F1 or F3), probed with anti-gp130. (D) Western blot analysis of total membranes of vegetative stage strain Ax3 (v) or $16 \mathrm{~h}$ developed strain Ax3 (d), an $n$-butanol extract of vegetative cell membranes (b), or purified s-gp130 (fraction 56), with an antibody against the core a3-Fuc epitope. (E) Comparison of s-gp130 with gp130 from normal cells and Olinked glycosylation mutants. SDS/PAGE (7.5\% acrylamide)/Western blot of extracts (100 $\mu \mathrm{g}$ protein) of the gp130-KO strain (KO), normal strain Ax3 (a), the $\operatorname{modB}$ mutant strain HW11 (b), the modC/gmd mutant strain HL250 (c), and strain CC11 expressing s-gp130 (s), were probed with anti-gp130. Two blots, aligned by replicates of sample a, are merged. (F) s-gp130 and partially purified gp130, before and after digestion with Endo H, were separated on a 4-12\% Bis-Tris SDS-PAGE gel, and Western blotted using anti-gp130.

Table 1. $M_{\mathrm{r}}$ Measurements of gp130 and s-gp130

\begin{tabular}{lllll}
\hline & \multirow{2}{*}{$\begin{array}{c}\text { calculated } \\
\text { sample }\end{array}$} & \multicolumn{3}{c}{ apparent $M_{r}$} \\
\cline { 3 - 5 } & polypeptide $M_{r}$ & Untreated & PNGaseF & MALDI-TOF-MS \\
\cline { 3 - 5 } gp130 & $79864^{\mathrm{a}}$ & 130000 & - & - \\
S-gp130 & $81666^{\mathrm{b}}$ & 133000 & 104000 & 115000
\end{tabular}

a. After processing of $\mathrm{N}$ - and $\mathrm{C}$-terminal signals, but not including potential GPI anchor.

b. After processing of $\mathrm{N}$-terminal signal.

gp130 Dictyostelium peptide sequences in MASCOT searches of the proteomic data (below, not shown). The s-gp130 band labeled with mAb 9E10 (not shown), which recognizes the Cterminal c-myc epitope tag, and exhibited an apparent $M_{\mathrm{r}}$ indistinguishable from that of endogenous gp130 (Figure 2E), indicating a similar degree of overall glycosylation.

s-gp130 is Highly N-glycosylated. The predicted sequence of gp130 contains $18 \mathrm{~N}$-sequons (N-x-S/T where $\mathrm{x} \neq \mathrm{P}$ ) as potential sites of N-glycosylation, as shown in Figure 1. Treatment of s-gp130 with PNGase F (which cleaves the GlcNAcAsn linkage) reduced its apparent $M_{\mathrm{r}}$ by $\sim 29,000$, from 133 000, based on SDS-PAGE (Figure 2C, Table 1), consistent with the loss of $\sim 14 \mathrm{~N}$-glycans with an average $M_{\mathrm{r}}$ of 2,124 (see below). However, $M_{\mathrm{r}}$ estimates based on SDS-PAGE are subject to error, and an average apparent $M_{r}$ of 115,000 for s-gp130 was estimated by MALDI-TOF-MS (Table 1). Interestingly, s-gp130 became more heterodisperse after PNGase F treatment (Figure 2C), unlike control incubations lacking PNGase F, regardless of whether s-gp130 was denatured with SDS or urea, or subjected to varied PNGase treatments (different amounts, multiple additions, longer incubation periods). This suggested that varying numbers per polypeptide of additional, PNGase F-resistant N-glycans may occur on s-gp130, and that the total number of N-glycans per polypeptide was more constant. Similar results were seen after release of $\mathrm{N}$-glycans from either s-gp130 or partially purified gp130 using Endo H ((Figure 2F), which cleaves between the 2 core GlcNAc residues, indicating that this feature is also shared with native gp130.
Table 2. Monosaccharide Composition of s-gp130

\begin{tabular}{|c|c|c|c|c|c|c|}
\hline \multirow[b]{2}{*}{ sample } & \multicolumn{3}{|c|}{$\begin{array}{l}\text { monosaccharide, } \\
\text { pmols }\end{array}$} & \multicolumn{3}{|c|}{$\begin{array}{c}\text { ratio of } \\
\text { monosaccharides }\end{array}$} \\
\hline & Fuc & $\mathrm{GlcN}^{\mathrm{a}}$ & Man & Fuc & $\mathrm{GlcN}^{a}$ & Man \\
\hline Untreated s-gp130 & 160 & 1530 & 2240 & 0.1 & 1.0 & 1.5 \\
\hline $\begin{array}{l}\text { PNGase F-released } \\
\text { glycans }\end{array}$ & 30 & $970(63 \%)$ & $1620(71 \%)$ & 0.0 & 1.0 & 1.7 \\
\hline $\begin{array}{l}\text { PNGase F-treated } \\
\text { s-gp130 }\end{array}$ & 34 & 177 (11\%) & $320(8 \%)$ & 0.2 & 1.0 & 1.8 \\
\hline
\end{tabular}

The total sugar content of s-gp130 was determined before and after PNGase F digestion by HPAEC-PAD analysis of acid hydrolysates. s-gp130 contained Fuc, glucosamine (assumed to derive from GlcNAc), and Man in a 0.1:1.0:1.5 molar ratio (Table 2). Acidic sugars were not detected. Based on amino acid analysis and assuming an average of 3 GlcNAc/N-glycan (see below), N-glycans numbered 13.7/polypeptide, consistent with the estimate above. Glycans removed by PNGase F contained GlcNAc and Man (1:1.7 molar ratio), and a trace of Fuc. However, about $17 \%$ of the monosaccharides (11\% of total initially measured) were detected after PNGase F deglycosylation and contained Fuc, GlcNAc and Man (0.2:1:1.8 molar ratio). The composition of residual sugars was consistent with an average of 2 additional fucosylated N-glycans/polypeptide, expected to be resistant to PNGase F-release if Fuc were a3-linked to the core GlcNAc as previously described. ${ }^{22,29}$

No evidence for O-glycans was observed using reductive $\beta$-elimination with sodium hydroxide followed by permethylation, or $\mathrm{NH}_{3}$-based $\beta$-elimination followed by $2 \mathrm{AB}$ labeling, RP-HPLC and fluorescence detection (data not shown). Furthermore, the apparent $M_{\mathrm{r}}$ of gp130 in $\operatorname{modB}$ - and $\operatorname{modC}$ mutant strains, which are defective in global mucin-type O-glycosylation $^{23,26}$ or fucosylation ${ }^{42}$ respectively, was unaffected, within the resolution and detection limits of SDS-PAGE and Western blotting (Figure 2E). Thus, unlike D. discoideum spore coat proteins previously analyzed by these methods, ${ }^{42,} 43$ gp130 and s-gp130 are not extensively, if at all, O-glycosylated. 


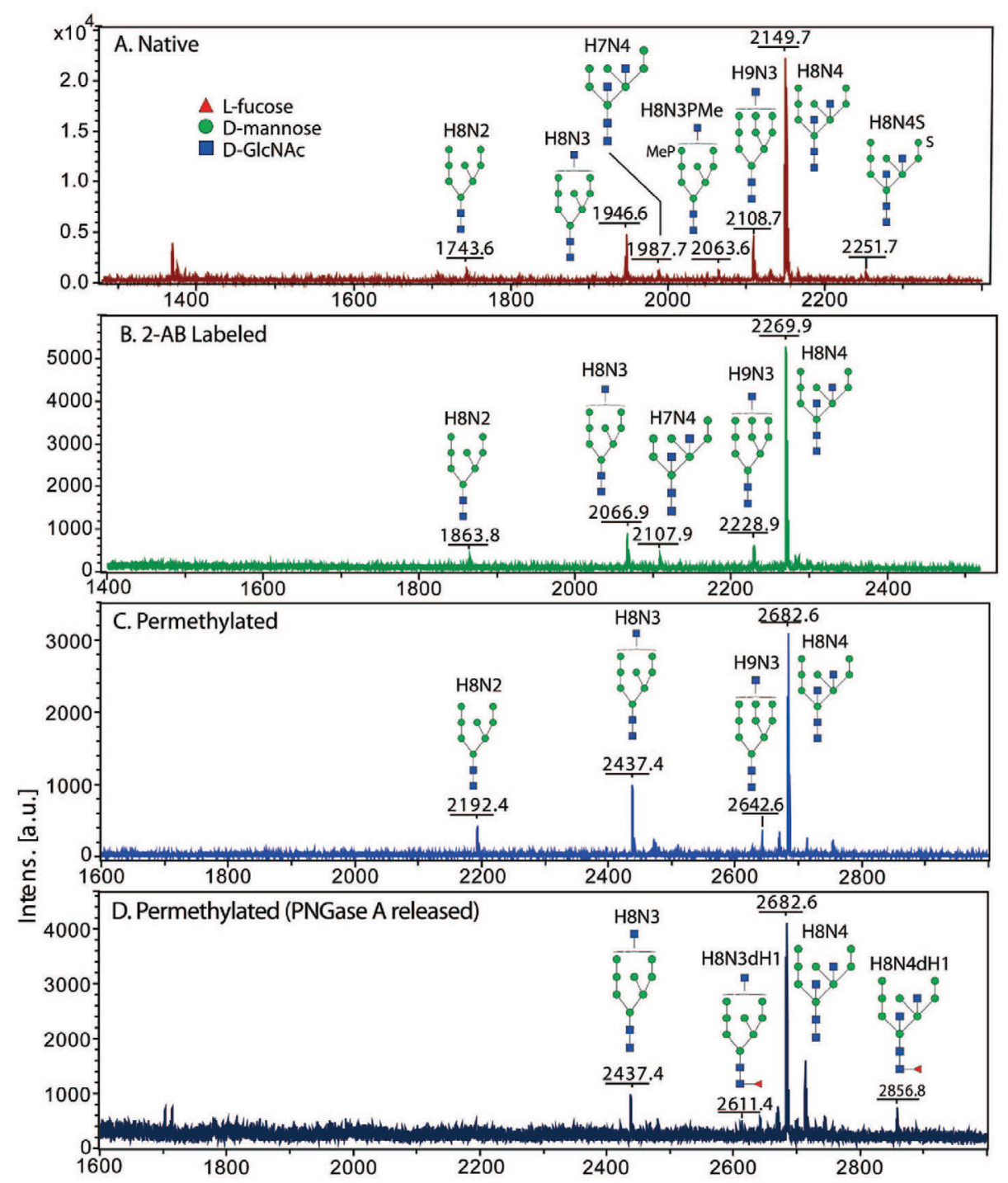

Figure 3. Glycomic analysis of N-glycans from s-gp130. (A) N-glycans were released by PNGase F from trypsin-treated s-gp130 and profiled by MALDI-TOF-MS in positive ion mode. (B) N-glycans were conjugated with $2 \mathrm{AB}$ prior to MS analysis. (C) N-glycans were permethylated prior to analysis. The similarity of the profiles obtained is emphasized by differential compression of $m / z$ scales to compensate for mass differences contributed by the derivatizations. The composition of the major species is $\mathrm{H} 8 \mathrm{~N} 4(\mathrm{H}=\mathrm{Hexose}, \mathrm{N}=\mathrm{N}$-acetyl-Hexosamine, $\mathrm{dH}=\mathrm{de}-$ oxyHexose) which, based on the monosaccharide composition analysis (Table 2) and other data (below), was assigned as Man 8 GlcNAc 4 . (D) Similar analysis of permethylated N-glycans released by PNGase A from pepsin-digested s-gp130, revealing additional low abundance fucosylated species. All ions were singly charged and monosodiated with the exception of the sulfated and methyl-phosphorylated ions in panel A, which were $[\mathrm{M}+2 \mathrm{Na}-\mathrm{H}]^{+}$, as listed in Table 3. Models depicting the most likely structure corresponding to each composition (see text and below) employ Consortium for Functional Glycomics (http://www.functionalglycomics.org/static/consortium/) notation.

N-Glycans from s-gp130. PNGase F-released glycans were recovered, permethylated, and profiled by MALDI-TOFMS. A series of sodium-adducted ions was observed that corresponded to $\mathrm{N}$-glycans with varying hexose $(\mathrm{H}=\mathrm{Hex})$ and $\mathrm{N}$-acetylhexosamine $(\mathrm{N}=\mathrm{HexNAc})$ compositions. The most abundant species matched a glycan with the composition of $\mathrm{H} 8 \mathrm{~N} 4$, with less intense signals corresponding to H8N3, H8N2, and H9N3 (Figure 3C). N-glycans were also analyzed without permethylation after labeling their reducing termini with $2 \mathrm{AB}$ (Figure 3B), which yielded a similar profile except for the addition of H7N4. Direct analysis of underivatized Nglycans revealed, in addition to these neutral glycans, lower abundance species that appeared to be sulfated or methylphosphorylated (Figure 3A), as discussed below. The major ions of each of the three spectral profiles corresponded to the same predicted glycan compositions, so relative preva- lence did not result from a bias resulting from derivatization. Based on the monosaccharide composition analysis, H8N4 was assigned as $\mathrm{Man}_{8} \mathrm{GlcNAc}_{4}$, with less abundant ions corresponding to species containing 2-4 GlcNAc residues and 7-9 Man residues. Predicted structures in Figure 3 are based on prior evidence that Dictyostelium forms the traditional Man${ }_{9} \mathrm{GlcNAc}_{2}$ structure after deglucosylation. ${ }^{21} \mathrm{Man}_{8} \mathrm{GlcNAc}_{2}$ is depicted as the product of ER-mannosidase-I acting on the Barm ${ }^{44}$ but the possibility that Man removal occurs from the Aarm (a3Man-linked) cannot be excluded. ${ }^{45}$ Positions of the peripheral GlcNAc residues are discussed below.

To search for potential PNGase F-resistant N-glycans, s-gp130 was digested with pepsin and PNGase A, an N-glycanase that preferentially acts on short peptides and can cleave $\mathrm{N}$-glycans modified with a3-Fuc on the reducing end GlcNAc. $\mathrm{N}$-glycans released by this method were similar to the PNGase 
Table 3. N-Glycans Detected on s-gp130a

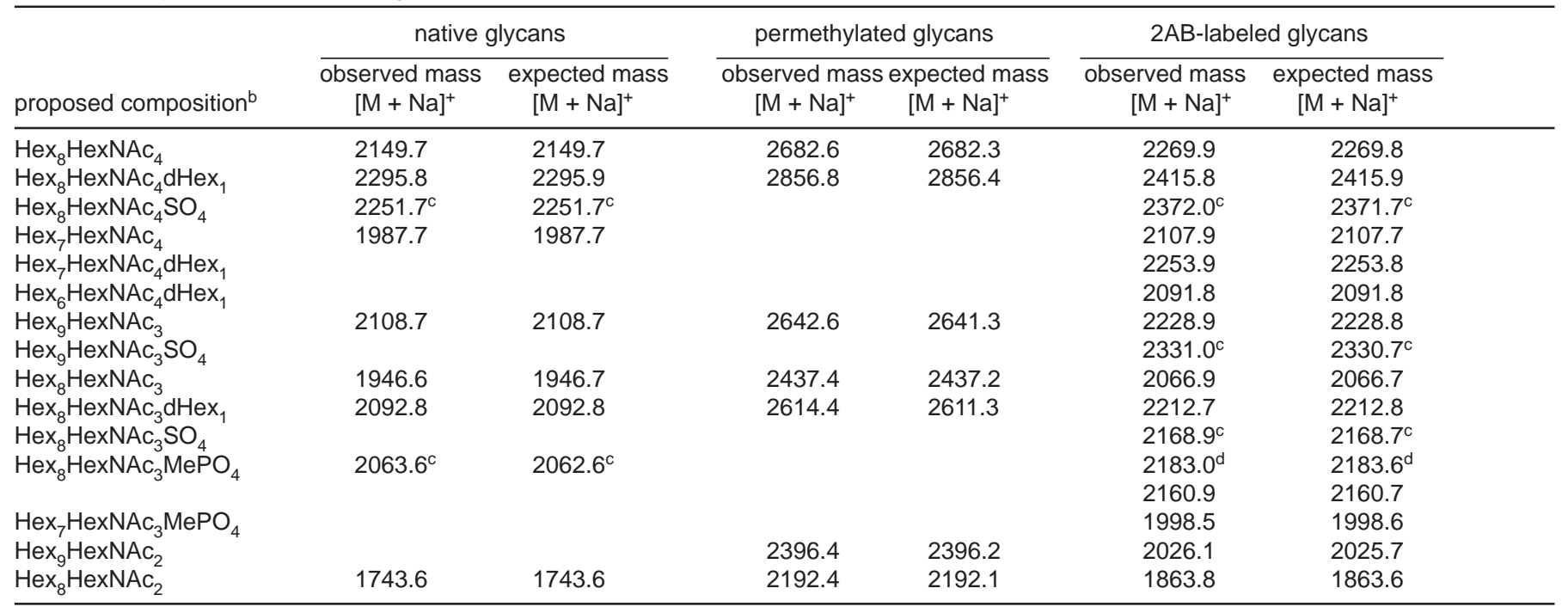

a. Data are from MALDI-TOF-MS analyses of PNGase-released glycans.

b. Based on composition analyses (Table 2), Hex = Man, HexNAc = GlcNAc, dHex = Fuc

c. lons are $[\mathrm{M}+2 \mathrm{Na}-\mathrm{H}]^{+}$; also detected in - ion mode (see Figure 5).

d. Ions are a mixture of $[\mathrm{M}+\mathrm{Na}]^{+}$and $[\mathrm{M}+2 \mathrm{Na}-\mathrm{H}]^{+}$; also detected in - ion mode (see Figure 5).

F-released glycans, with $\mathrm{Man}_{8} \mathrm{GlCNAc}_{4}$ and $\mathrm{Man}_{8} \mathrm{GlCNAc}_{3}$ being the most prevalent glycans detected (Figure 3D). In addition, related species assigned as $\mathrm{Man}_{8} \mathrm{GlcNAc}_{4} \mathrm{Fuc}$ and Man${ }_{8} \mathrm{GlcNAc}_{3}$ Fuc were detected at lower abundance. Since known peripheral Fuc linkages do not interfere with PNGase F cleavage, and a core a1,3-fucosyltransferase activity and core a3linked Fuc have been detected in Dictyostelium, ${ }^{29}, 22$ these monofucosylated species were predicted to contain the core Fuca1,3GlcNAc linkage as depicted in Figure 3D. Consistent with this model, core-linked Fuc was detected during MS/MS analysis of a glycopeptide containing site 7 (see below). To confirm occurrence of the a3-linkage, s-gp130 was probed with antisera against HRP, a glycoprotein with immunogenic a3-linked core Fuc on its N-glycans. ${ }^{46}$ An affinity-purified fraction reacted specifically with s-gp130 (Figure 2D), but an affinity-depleted fraction did not (not shown). Since s-gp130 expresses the HRPfucose epitope, Fuc is likely a3-linked to the core GlcNAc. The most highly reactive band of vegetative cell membranes and an $n$-butanol extract enriched in GPI-anchored membrane proteins (lanes v and b) comigrated with gp130. Thus, gp130 may be the major carrier of core-fucosylated N-glycans in vegetative cells. As expected, ${ }^{22,}{ }^{29}$ developing cells (lane d) expressed much higher levels of core-fucosylated N-glycans.

High-Mannose Glycans with Terminal GlcNAc Moieties at Branched Man Residues. Previous studies described a $\mathrm{Man}_{8} \mathrm{GlcNAc}_{3}$ species consisting of a canonical high-mannose glycan substituted with a GlcNAc residue $\beta 4$-linked to the a6-Man linked to the $\beta$-Man (intersecting), ${ }^{45}$ and a Man${ }_{8} \mathrm{GlcNAc}_{4}$ species containing both the intersecting GlcNAc and a $\beta 4$-GlcNAc on the $\beta$-linked Man (bisecting). ${ }^{47}$ A recent MSbased glycomics analysis confirmed the existence of this species. ${ }^{22}$ To address the similarity of $\mathrm{Man}_{8} \mathrm{GlcNAc}_{4}$ on s-gp130 to this structure, $\mathrm{Man}_{8} \mathrm{GlcNAc}_{4}-2 \mathrm{AB}$ was isolated by RP-HPLC and digested with Jack Bean $\beta$-hexosaminidase or Jack Bean a-mannosidase. Man $_{9} \mathrm{GlcNAc}_{3}-2 \mathrm{AB}$ was analyzed for comparison. The glycans were unaffected by $\beta$-hexosaminidase (data not shown), as expected if the GlcNAc residues were located at bisecting or intersecting positions protected from enzyme access. Three major products $[\mathrm{H}(5-7) \mathrm{N} 4-2 \mathrm{AB}]$ were observed after a-mannosidase digestion of $\mathrm{Man}_{8} \mathrm{GlcNAc}_{4}-2 \mathrm{AB}$ (Figures
S1A and B, Supporting Information). The smallest product, $\mathrm{H} 5 \mathrm{~N} 4-2 \mathrm{AB}$, likely resulted from inaccessibility of the remaining mannoses due to steric interference by intersecting and bisecting GlcNAc residues. This assignment is supported by detection of a prominent ion corresponding to H3N4-2AB in an MS/MS-CID experiment like that shown in Figure 4 (below). Partial steric interference by the GlcNAc residues may result in partial accumulation of larger products, which were reliably detected in multiple trials using the highest a-mannosidase amounts tolerated by MS protocols, as also observed previously. ${ }^{22,} 48$ a-mannosidase may also be susceptible to product inhibition by free Man. Digestion of $\mathrm{Man}_{9} \mathrm{GlCNAc}_{3}-2 \mathrm{AB}$ with a-mannosidase yielded a mixture of $\mathrm{H}(4-6) \mathrm{N} 3-2 \mathrm{AB}$ species (Supplementary Figure S1C and D, Supporting Information). The presence of H4N3-2AB is most consistent with an intersecting GlcNAc in the original structure.

Further information about the positions of the GlcNAc residues was inferred from diagnostic fragment ions from MALDI-TOF/TOF CID experiments. The $[\mathrm{M}+\mathrm{Na}]^{+}$ion of $\mathrm{Man}_{8} \mathrm{GlcNAc}_{4}-2 \mathrm{AB}$ yielded $\mathrm{B}$ and $\mathrm{Y}$ type fragment ions that demonstrated a series of Man and GlcNAc losses (Figure 4). In the low $m / z$ range, two $B$ type ions 163.15 and 204.17 indicated terminal Man and GlcNAc respectively. Also observed were ions $m / z$ 325.18, a B fragment ion of 2 Man, and a weak ion at 487.5 corresponding to $\mathrm{B}$ ion of 3 Man. Fragment ions $528.23(\mathrm{H} 2 \mathrm{~N} 1-2 \mathrm{AB})$ and 690.24 (H3N1-2AB) were most consistent with substitution of GlcNAc at the intersecting position. The ion at $m / z 893.3$ matches H1N3-2AB, which indicated a bisecting GlcNAc on the core $\beta$-mannose. The presence of the H3N4-2AB ion at $m / z 1401.5$ was most consistent with substitution of peripheral GlcNAcs at both intersecting and bisecting GlcNAcs. Although the possibility that GlcNAc is terminal to monosubstituted Man was not excluded by the fragment profile, this configuration would be expected to be sensitive to $\beta$-hexosaminidase digestion, which was not observed (see above). Thus the $\mathrm{Man}_{8} \mathrm{GlcNAc}_{4}$ isomer found on s-gp130 likely corresponds to the bisecting/intersecting GlcNAc structure previously described on bulk N-glycans.45, 47, 22

Sulfated and Phosphorylated N-Glycans. To investigate the possibility of additional glycan types that may occur at 


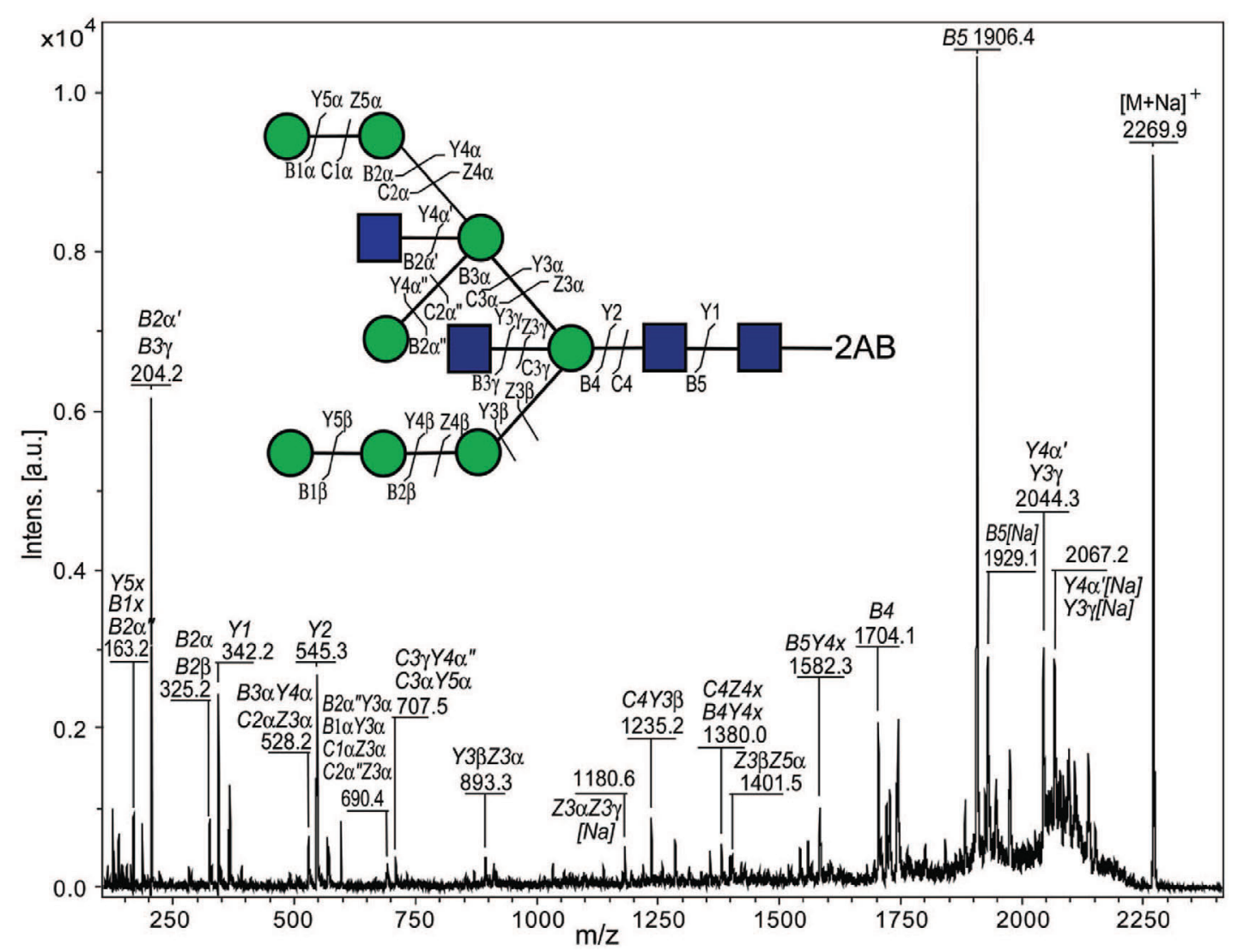

Figure 4. MS/MS of glycan H8N4-2AB with intersecting and bisecting GlcNAc residues. Fragmentation spectrum of H8N4-2AB $\left([\mathrm{M}+\mathrm{Na}]^{+}\right.$ 2269.9) after LID/heCID in a MALDI-TOF/TOF instrument showed abundant B- and Y-type fragment ions, ${ }^{49}$ which are interpreted by the proposed structure (inset) as described in the text.

low abundance or ionize poorly in the presence of other glycans, PNGase F-released, 2AB-labeled N-glycans were resolved by RP-HPLC. MALDI-TOF-MS analysis of fluorescent fractions confirmed the above glycans and provided further evidence for sulfated and methyl-phosphorylated N-glycans. For example, the positive ion spectrum of one fraction indicated sodiated H8N3-2AB and H9N3-2AB and, in addition, singly charged ions matching the $m / z$ of $\mathrm{H}_{8 \mathrm{~N}} 4 \mathrm{SO}_{4}-2 \mathrm{AB}$, $\mathrm{H} 8 \mathrm{~N}_{3} \mathrm{SO}_{4}-2 \mathrm{AB}, \mathrm{H}_{9} 3 \mathrm{SO}_{4}-2 \mathrm{AB}$ and $\mathrm{H} 8 \mathrm{~N} 3 \mathrm{MePO}_{4}-2 \mathrm{AB}$ (Figure $5 \mathrm{~A})$. Each sulfated glycan was observed as a single disodiated$\mathrm{H}$ species, similar to previous results with sulfated glycans. ${ }^{50}$, ${ }^{51}$ A methyl-phosphorylated glycan was observed as a pair of ions corresponding to a sodium adducted only and sodium adducted with sodium-proton exchange equal to the number of phosphate groups, consistent with properties of reductively aminated (2-AEAB labeled) high mannose phosphomonoester standards. ${ }^{52,53}$ In negative ion mode (Figure 5B), only [M $-\mathrm{H}]^{-}$ions corresponding to the sulfated or methyl-phosphorylated glycans were observed, providing strong support for their postulated anionic nature. $\mathrm{H} 8 \mathrm{~N} 4 \mathrm{SO}_{4}-2 \mathrm{AB}$ and $\mathrm{H}_{8 \mathrm{~N}} 3 \mathrm{SO}_{4}$ $2 \mathrm{AB}$ likely correspond to the GlcNAc-intersected and/or -bisected $\mathrm{Man}_{8}$-species described above, with a $6-\mathrm{O}-\mathrm{SO}_{3}$-moiety on a peripheral Man as described previously for radiolabeled Dictyostelium glycans using non-MS methods. ${ }^{54} \mathrm{H} 8 \mathrm{~N} 3 \mathrm{MePO}_{4}$ $2 \mathrm{AB}$ likely represents $\mathrm{Man}_{8} \mathrm{GlcNAc}_{3} \mathrm{MePO}_{4}-2 \mathrm{AB}$, modified with a 6- $\mathrm{MePO}_{4}$-moiety on a peripheral Man, as also previously described on radiolabeled Dictyostelium glycans. ${ }^{55,} 56$ $\mathrm{Man}_{8} \mathrm{GlcNAc}_{4} \mathrm{SO}_{4}$ and $\mathrm{Man}_{8} \mathrm{GlCNAc}_{3} \mathrm{MePO}_{4}$ were abundant enough to be detected in the positive ion mode profile of underivatized s-gp130 N-glycans shown in Figure 3A.
Determination of Sites of Glycosylation of s-gp130. Occupancy of potential glycosylation sites, or N-sequons, was assessed using complementary strategies. Four nonglycosylated $\mathrm{N}$-sequons were initially identified by detection of unglycosylated peptide ions in a tryptic digest, using MALDI-TOF-MS and confirmed by MS/MS analysis as summarized in Table S1 (Supporting Information). Glycosylated sequons were identified by the appearance, after PNGase F treatment, of peptides whose mass was increased by 0.98 Da due to the Asn to Asp conversion associated with glycan release. In the MALDITOF-MS comparison of tryptic peptides from before and after PNGase F treatment shown in Figure S2 (Supporting Information), new ions seen after deglycosylation were mapped to predicted tryptic fragments, and fragmentation by MALDITOF/TOF or ESI-QTOF was performed to confirm the site of glycosylation. This approach led to the identification of seven glycopeptides (Table S1, Supporting Information). Treatment of the tryptic digest with Endo $\mathrm{H}$, which leaves a residual GlcNAc tag, confirmed the findings and led to the identification of an additional modified sequon (Table S1, Supporting Information). Detection of both nonglycosylated and modified versions of the same peptide indicated that these sequons are variably modified.

These approaches failed to detect peptides harboring 6 of the $18 \mathrm{~N}$-sequons. To improve coverage, peptides were generated using pepsin or sequential addition of trypsin and chymotrypsin, and deglycosylated using PNGase A or PNGase F respectively. In addition, glycopeptides were pre-enriched using hydrophilic interaction chromatography or Con A lectin affinity chromatography (see Experimental Procedures) and de- 


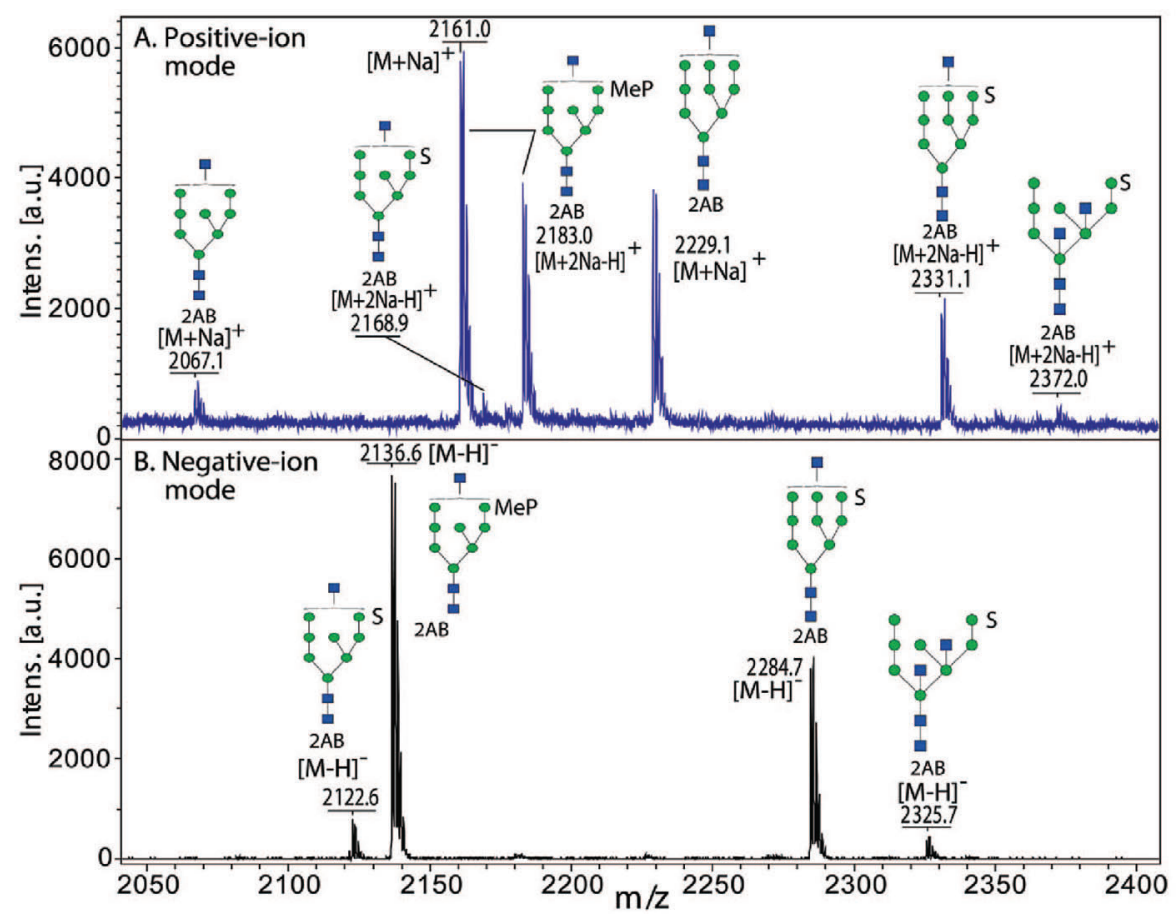

Figure 5. Anionic N-glycans of s-gp130. PNGase F-released glycans were 2AB-labeled and fractionated by RP-HPLC. MALDI-TOF-MS analysis of a fluorescent fraction containing candidate sulfated (S) and methyl-phosphorylated (MeP) N-glycans is shown in positive (A) and negative (B) ion modes. Glycan adduct types are as indicated, and comparisons with theoretical $\mathrm{m} / \mathrm{z}$ values are listed in Table 3. See text for basis of structural predictions.

glycosylated using PNGase $\mathrm{F}$ in $50 \% \mathrm{H}_{2}^{18} \mathrm{O}$. Deglycosylated peptides (singly charged) were readily apparent as doublets (spaced by $2 \mathrm{Da}$ ), and subjected to MS/MS sequencing (data not shown). The status of each $\mathrm{N}$-glycosylation site, inferred from these studies and from direct detection of glycopeptides as described in the next section, is summarized in Table 4. Evidence was obtained for glycosylation of 15 of the $18 \mathrm{~N}$-sequons. Seven sites were partially utilized and the remainder appeared to be fully occupied, though the possibility of their occasional non-utilization cannot be excluded. The partially utilized Nsequons appear to be distributed throughout the length of the s-gp130 polypeptide (shown in blue in Figure 1).

Identification of Glycopeptide Glycans. Glycopeptides were also detected directly, based on (1) mass matches with a conceptual [glycan+peptide] combinations, (2) occurrence of neutral losses of Hex, HexNAc, and/or Fuc in the MS/MS spectrum, (3) presence of glycan oxonium ions and [peptide + GlcNAc] as a dominant fragment ion in the MS/MS spectrum, (4) overlapping elution time with other glycopeptide glycoforms (see Figure 6 below), and (5) loss of the ion after PNGase A or PNGase F treatment. In some cases, midlevel confidence was based on satisfaction of the first and last criteria. As summarized in Table 5, 60 distinct glycopeptides assignable to 14 different N-sequons were directly identified using MALDITOF/TOF-MS, LC-Q-TOF, and LC-LTQ instruments.

Two examples of high-level confidence assignments are shown in Figure S3. In panel A, a tryptic ion $[\mathrm{m} / z 1138.73(+3)]$ was assigned as NIDFTNVTYMK with a $\mathrm{Man}_{9} \mathrm{GlcNAc}_{3}$ glycan at site 8 . At the low mass end, the presence of sugar oxonium ions $\left(\left[\mathrm{Hex}-\mathrm{H}_{2} \mathrm{O}+\mathrm{H}\right]^{+}, 162 ;\left[\mathrm{HexNAc}-\mathrm{H}_{2} \mathrm{O}+\mathrm{H}\right]^{+}, 204\right.$; $[\mathrm{Hex} 2$ $\left.\left.-\mathrm{H}_{2} \mathrm{O}+\mathrm{H}\right]^{+}, 324\right)$ were indicative of a glycopeptide. At the higher end of the $m / z$ range, fragmentation of the glycopeptide gave predominantly sequential losses of hexose residues until a fragment ion for the peptide and a single GlcNAc was observed. GlcNAc was assumed to be amide-linked to the side chain of the Asn in the single N-sequon (NVT) present on this peptide. In panel B, a tryptic/chymotryptic ion $[m / z 1174.47(+3)]$ was identified as FEQSITNLTTL modified with $\mathrm{Man}_{8} \mathrm{GlcNAc}_{4} \mathrm{Fuc}_{1}$ at site 7 . The presence of [peptide $+\mathrm{GlcNAc}]^{2+}$ and [peptide + GlcNAc + Fuc $]^{2+}$ ions showed that Fuc is attached to the core GlcNAc, consistent with the glycomic results above.

The most prevalent glycoforms determined by the glycomics analysis of s-gp130 (H8N4, H8N4F, H8N3, H8N3F, H9N2, and H8N2; Figure 3 and Table 3) were the most frequently observed glycoforms on glycopeptides (Table 5). For example, H8N4 and H8N4F were detected at 6 and 7 sites, respectively, whereas the lower abundance glycoforms were often found at only one or two sites. In addition, glycans at individual sites were, in many cases, highly heterogeneous. For example, 12 different glycans were detected at site 1 (NTT), including several not detected in the glycomic approach. Eight were seen in a single LC-MS analysis of a tryptic/chymotryptic digest, as shown in the composite of all ions eluted in the interval from 13.8-14.8 min (Figure 6A). Most assignments were confirmed by MS/MS on individual scans such as shown in panel B. An example at $m / z 1071.05$ (H8N3F2) possessed a bisecting GlcNAc and a core Fuc, based on detection of an H1N3F1peptide fragment ion. In addition, this and other structures in this series appeared to possess a previously described terminal Man-linked Fuc, ${ }^{57,} 58$ based on a prominent fragment ion resulting from simultaneous loss of [Hex $+\mathrm{dHex}]$ from the parent ion (not shown). The glycopeptide characterizations confirmed that almost all glycans described in Table 4 were derived from s-gp130 rather than potential contaminants and, in addition, revealed previously undetected glycoforms.

\section{Discussion}

Dictyostelium N-Glycome. The N-glycome of the amoeboid stage of $D$. discoideum consists predominantly of high- 


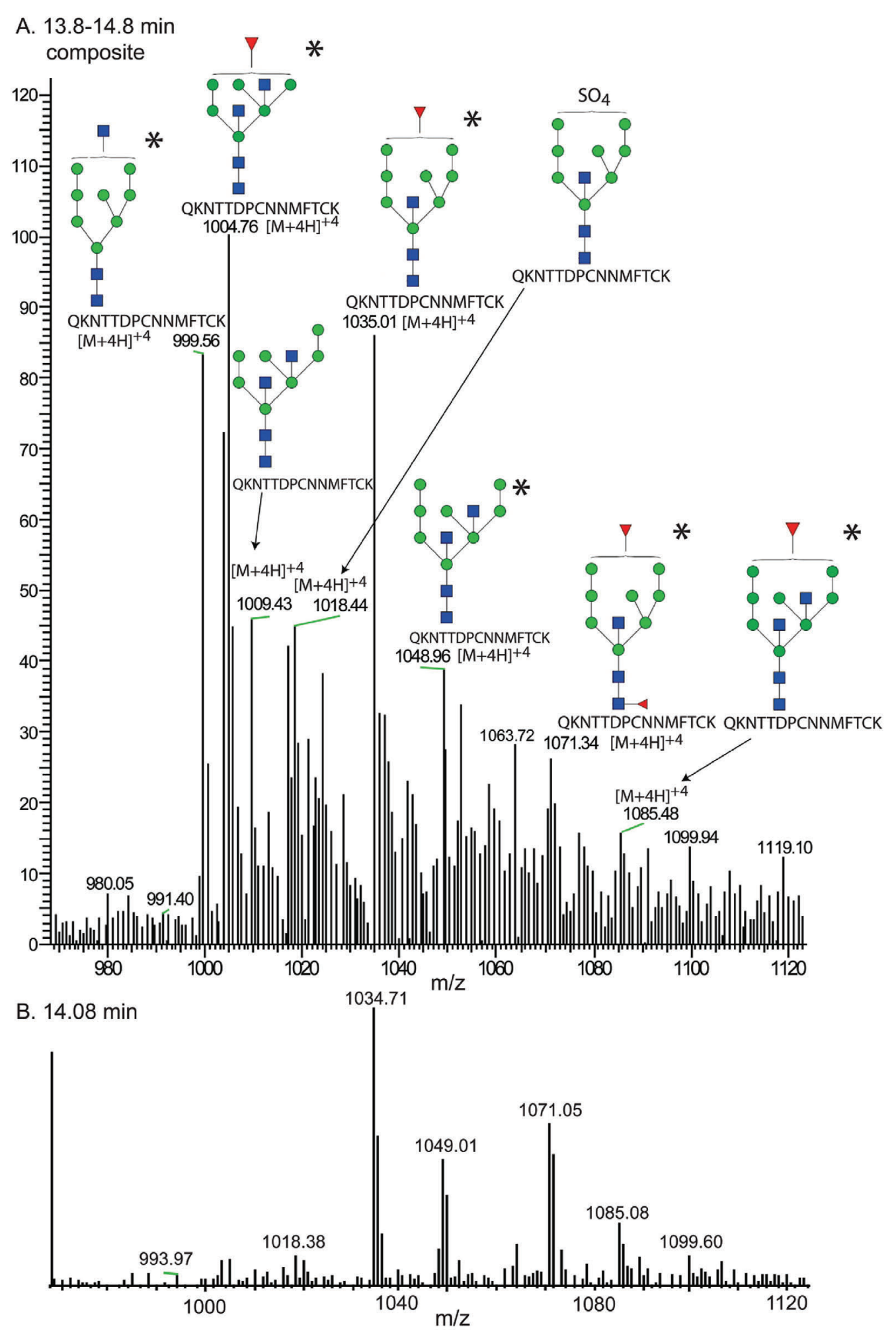

Figure 6. s-gp130 Glycopeptide Analysis using LC-MS/MS. Con A selected glycopeptides from a double digest (trypsin-chymotrypsin) were analyzed using LC-MS/MS (RP-HPLC on a Thermo LTQ XL). (A) Average MS spectrum of glycopeptides containing site 1 (QKNTTDPCLDNNMFTCK), during its elution (13.80-14.75 min) is shown. Eight glycoforms were detected, including H8N4, H8N4F, H7N4, H6N4F, H8N3, $\mathrm{H} 8 \mathrm{~N} 3 \mathrm{~F}$, and $\mathrm{H} 8 \mathrm{~N}_{3} \mathrm{SO}_{4}$, which were observed in the glycomic analysis, and a novel doubly fucosylated H8N3F2. (B) Representative spectrum at $14.08 \mathrm{~min}$ is shown to illustrate ions selected for MS/MS fragmentation (denoted by an *) in support of the structure models shown.

mannose $\left(\operatorname{Man}_{6-9}\right)$ structures whose cores are similar to those of the great majority of eukaryotes. ${ }^{21,22,11}$ The $D$. discoideum glycans are, however, specialized by modification with $\beta 4$ linked GlcNAc at the $\beta$-Man (bisecting), commonly observed for complex but not high-mannose N-glycans of animals, and at the Man a6-linked to the $\beta 4$-Man (intersecting) which is novel. Fuc, an uncommon modification of high-mannose glycans, occurs in a3-linkage (as in plants and invertebrates) and possibly in a6-linkage to the core GlcNAc, and on a peripheral Man. Substitution of peripheral Man residues with 6-O- 
Table 4. Identification of s-gp130 Glycosylation Sites

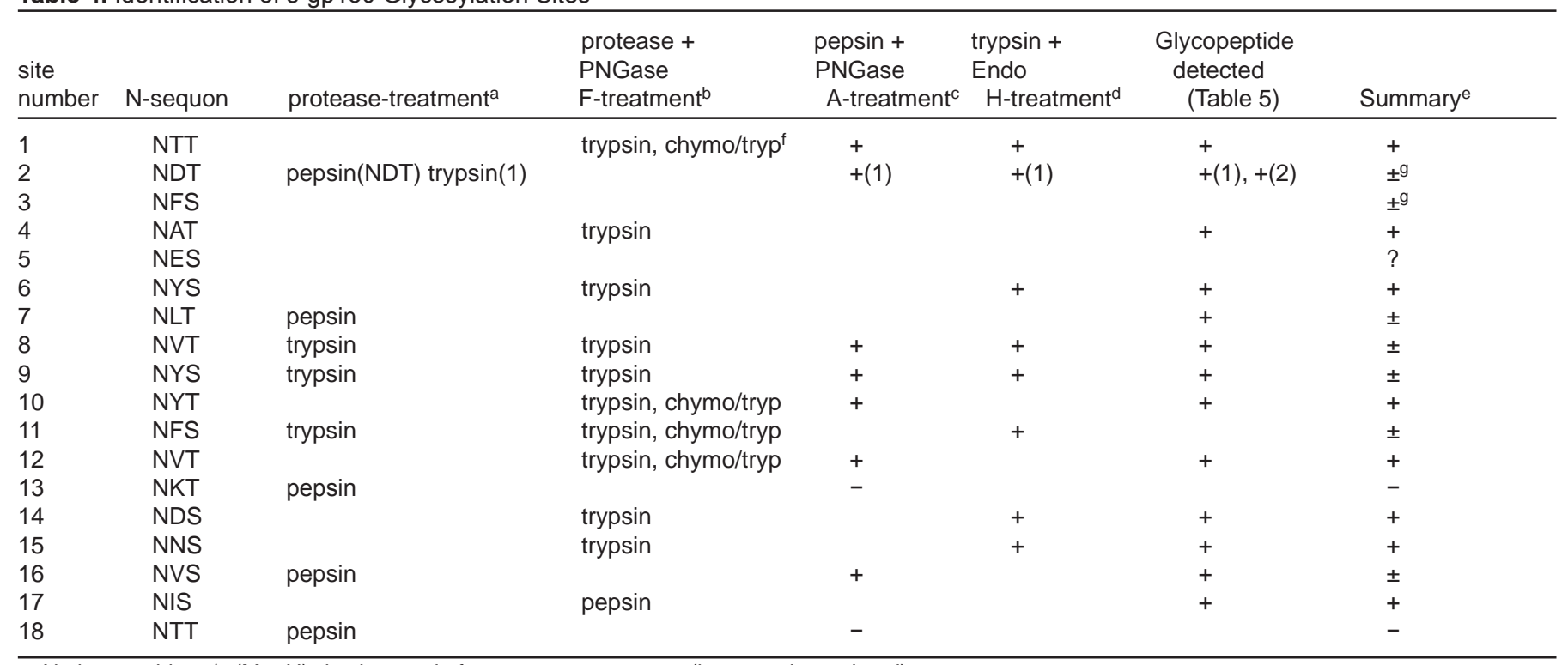

a. Native peptide $\mathrm{m} / \mathrm{z}(\mathrm{M}+\mathrm{H})^{+}$is observed after protease treatment (i.e., not glycosylated).

b. $m / z$ increment of 0.98 is observed after PNGase F treatment following the protease treatment indicated.

c. $\mathrm{m} / \mathrm{z}$ increment of 0.98 is observed after PNGase A treatment after pepsin digestion.

d. $\mathrm{m} / \mathrm{z}$ increment of 203.1 is observed after Endo $\mathrm{H}$ treatment after trypsin digestion.

e. + , only modified peptides detected; \pm , both modified and unmodified peptides detected; -, only unmodified peptide detected; ?, peptide not detected.

f. Combined treatment with chymotrypsin and trypsin.

g. Sites 2 and 3, found on the same tryptic peptide, were observed to be simultaneously occupied, exclusively occupied, or alternatively occupied.

$\mathrm{SO}_{3}$ or $6-\mathrm{O}-\mathrm{PO}_{3}-\mathrm{Me}$ is currently thought to be uncommon outside of the Dictyostelium lineage. The structures were originally defined in the 1980s and 1990s, by chromatographic analysis of changes effected by various exoglycosidases and selective chemical degradations, applied to PNGase F-, Endo $\mathrm{H}-$, and hydrazinolysis- released glycans, or Pronase-released glycopeptides, derived from cells metabolically labeled with $\left[{ }^{3} \mathrm{H}\right]$ Man, $\left[{ }^{3} \mathrm{H}\right] \mathrm{GlcNH}_{2},{ }^{35} \mathrm{SO}_{4^{\prime}}{ }^{32} \mathrm{PO}_{4}$, and other precursors. ${ }^{21,57}$ Very recently and while this study was in progress, mass spectrometry methods confirmed the occurrence of high-mannose $\mathrm{N}$-glycans variably substituted with intersecting and bisecting GlcNAc and core a3Fuc but, notably, core-a6-fucosylated, peripherally fucosylated, and anionic N-glycans were not detected. ${ }^{22}$ Annotation of the $D$. discoideum genome revealed greater than 80 glycosyltransferase and glycophosphotransferase genes, over half of which probably contribute to formation of the N-glycome. ${ }^{59,11}$

s-gp130 N-Glycome. This study characterizes the glycome of a single, extensively glycosylated cell surface protein, using mainly MS and MS/MS methods. The analysis was performed on a homologously expressed version of gp130 in which the C-terminal (presumptive GPI-anchor-directing) sequence was replaced with the myc-epitope tag. s-gp130 was purified essentially to homogeneity based on chromatographic criteria and equivalence of silver staining and anti-gp130 labeling after SDS-PAGE (Figures 2A-C). Evidence was obtained for glycosylation of 15 of the $18 \mathrm{~N}$-sequons of s-gp130 (Table 4), and there was an average of $\sim 15 \mathrm{~N}$-glycans/polypeptide. Analyses of N-glycans released enzymatically from s-gp130, which represented the great majority based on sugar composition analysis, revealed predominantly a $\mathrm{Man}_{8} \mathrm{GlcNAc}_{4}$ structure (Figure 3) possessing both bisecting and intersecting GlcNAc residues based on exoglycosidase digestions and MS/MS CID studies (Figure 4). A similar conclusion was drawn from 3 types of preparations (native, permethylated, and $2 \mathrm{AB}$-derivatized), indicating that the result was independent of method. Addition- ally observed were lower abundance N-glycan types (Table 3) that spanned the range of the N-glycan substituents defined by the original glycomic analyses performed on isotopically labeled material as summarized above. In the neutral class, the number of Man residues ranged from 6-9, peripheral GlcNAc residues ranged from $0-2$, and Fuc ranged from $0-2$. Peripheral GlcNAc residues could be located at the bisecting or intersecting positions or both (Figures 4, 6, and S3, Supporting Information). Fuc was predominantly a3-linked to the core GlcNAc, because most Fuc was resistant to release by PNGase F (Table 2 and Figure 3), indicating that it was not a6-linked to the core GlcNAc, the core a3-Fuc epitope was detected using an anti-HRP antibody (Figure 2D), and MS/MS studies located Fuc on the core GlcNAc (Figure S3B, Supporting Information). This assignment is consistent with results from the recent analysis of the total cellular N-glycome. ${ }^{22}$ However, Fuc in a peripheral linkage was also observed based on MS/ MS analysis of site 1 glycopeptides (Figure 6), consistent with trace levels of Fuc in PNGase F-released glycans (Table 2), and analysis of a difucosylated species on Site 1 (Figure 6) detected both core and peripheral Fuc. An average of 2 of the 14-16 Nglycans of s-gp130 was inferred to be core a3-fucosylated, primarily on GlcNAc-intersected and/or -bisected N-glycans.

Multiple anionic glycans also were detected (Figure 5). The assignment of three monosulfated species was based on mass matches in both the native glycan and 2AB-labeled pools, ionization as a disodiated (with $\mathrm{H}$-abstraction) species in positive ion mode, and selective detection in negative ion mode. The structures very likely correspond to the $6-\mathrm{O}-\mathrm{SO}_{3}-\mathrm{Man}$ modified N-glycans described previously. ${ }^{54}$ Methyl-phosphorylated 2AB-labeled N-glycans were assigned using similar criteria, but were distinguished from sulfated glycans by their ionization as a mixture of monosodiated and disodiated species in positive ion mode. These ions very likely correspond to a previously described ${ }^{55,56} \mathrm{~N}$-glycan with a peripheral 6-O$\mathrm{MePO}_{3}-\mathrm{Man}$ (phosphodiester) linkage. Phosphorylated gly- 
cans lacking a methyl cap, and multiply phosphorylated and/ or sulfated species, were not detected. The absence of these anionic structures in a recent MS study of total cell N-glycans ${ }^{22}$ may be due to differences in methodologies, as ions corresponding to these structures were abundant enough to be seen in a nonenriched glycomic profile of s-gp130 (Figure 3A).

s-gp130 N-Glycopeptidome. The general features of the s-gp130 N-glycome inferred from enzymatically released Nglycans were confirmed by direct analyses of the glycopeptides. Sixty glycopeptide ions associated with 14 glycosylation sites were assigned with varying degrees of confidence ranging from exact mass matching to MS/MS-CID support (Table 5, Figures 6 and S3, Supporting Information). Man ${ }_{8}$ GlcNAc${ }_{4}$ Fuc $_{0-1}$ species, which were the most abundant PNGase-released glycans, were also the most frequently observed modification, occurring at 10 different $\mathrm{N}$-sequons. All but two of the PNGase-released glycan types were detected on the glycopeptides, confirming s-gp130 as their source; the two not observed $\left(\mathrm{H} 7 \mathrm{~N}_{4} \mathrm{SO}_{4}\right.$ and $\mathrm{H} 8 \mathrm{~N} 3 \mathrm{MePO}_{4}$ ) differ by only a single Man residue. In contrast, 15 glycan types not revealed by the glycomic analyses were detected on peptides (compare Tables 5 and 3); most of the new glycans were however related by simple variations in the number of Man or GlcNAc residues. An exception was evidence for peripheral Man-linked Fuc (Figure 6) as described previously on radiolabeled material.57, 58 An even greater diversity of glycan types cannot be excluded but, since all major types defined by earlier studies using metabolic labeling were observed, novel glycans are likely to be related and of low abundance if they exist at all. Thus the glycoproteomic approach was better at revealing the diversity of glycosylation, whereas the glycomic approach was more suitable for revealing the relative abundance of glycan types.

Individual sites varied greatly in their modification status. Sites 1 and 8 were modified with up to 12 different glycans (Table 5), whereas only a single minimally processed glycan (Man${ }_{8} \mathrm{GlcNAc}_{2}$ ) was found at site 15. Methyl-phosphodiester N-glycans were observed at five sites and sulfated N-glycans were at four partially overlapping sites, suggesting preferential sites for anionic modification, and a peripheral Fuc residue was observed at only site 1 . In addition, seven sites exhibited variable occupancy and two sites appeared unoccupied (Table 4). Failure to modify Site 18 may be an artifact of its proximity to the Cterminus in the secreted construct. The mechanisms behind sitespecific variations are not known as structure information is not available for this glycoprotein. In summary, gp130 consists of thousands of glycoforms if heterogeneity at different sites is independent. These findings are consistent with an average site occupancy of 15 (of 18 total) for the full-length protein based on results from Table 1 and Figure $2 \mathrm{C}$ and $\mathrm{F}$.

Relevance to gp130. The N-glycosylation features observed on s-gp130 are potentially applicable to native gp130, because SDS-PAGE/Western blot analysis revealed a similar if not identical degree of $\mathrm{N}$-glycosylation (Figure 2E), and a comparison after Endo H-digestion indicated a similar fraction of resistant $\mathrm{N}$-glycans (Figure 2F) that are likely core a3-fucosylated. In addition, the most highly reactive band for anti-core a3Fuc in vegetative cells and in an $n$-butanol extract of vegetative cells, enriched in gp130 and other GPI-anchored proteins ${ }^{25}$ consistent with the sequence prediction that gp130 is GPI-anchored, comigrated with gp130. Thus, authentic gp130 appears to not only be core-fucosylated as for s-gp130, but may also be the major carrier of this structure in amoebae. Interestingly, N-glycans from the $n$-butanol pool were generally more fucosylated than from other cell fractions (data not shown), raising the possibil- ity that N-glycans of authentic gp130 are more fucosylated than those from s-gp130. However, confirmation of the profile of Nglycan structures on gp130 itself must await an efficient method to isolate the native glycoprotein. No O-glycans were detected in searches of material released by alkaline treatment, or in the glycopeptides, consistent with the absence of $M_{r}$ shifts in $\operatorname{modB}$ and modC mutant strains that affect O-glycosylated spore coat proteins (Figure 2E).

Though $\mathrm{Man}_{8}$ GlcNAc$_{4}$ was abundant in total amoeba Nglycans in a recent MS analysis, it was less prevalent than species with fewer Man residues and/or with core a3-Fuc.22 Therefore, although s-gp130 expresses a broad cross-section of the N-glycome, the skewed abundance profile of N-glycan types is indicative of protein- or compartment-specific specialization of s-gp130 N-glycan processing, in addition to site-specific processing as summarized above.

Potential Relevance to the Cell Surface Glycocalyx. gp130 is related to a family of 15 predicted proteins, as inferred from analysis of genome sequences and from biochemical studies (Table 6). These are all large proteins that exhibit $28-40 \%$ sequence identity and $38-48 \%$ similarity to gp130, and possess predicted signals for import into the rER and for GPIanchor addition. They each encode 4-31 N-sequons, with all but two having 9 or more. A major subfamily consists of the four gp138 glycoproteins, which are more similar to each other (82-87\% similarity and $77-85 \%$ identity using BESTFIT and $\mathrm{GAP}^{60}$ ) than to gp130. gp138 was originally implicated in sexual cell fusion events leading to the formation of macrocysts by $D$. discoideum, ${ }^{7,61}$ but tetra-knockout cells produce macrocysts leaving the function of the gp138 family unclear. ${ }^{8}$ Strikingly, the positions of the N-glycans are poorly conserved in this protein family (Table 6).

Relatives of these genes also occur in the genome sequence of D. purpureum, ${ }^{11}$ where the family is dramatically smaller with six predicted members that fulfill length and similarity criteria. The D. purpureum homologues also are predicted to be highly N-glycosylated, but again at unconserved sites compared to gp130 and to each other (Table 6). Although generally similar in length and identity to the D. discoideum homologues, the $D$. purpureum members are sufficiently diverged that it is difficult to assign orthologs. Overall, the protein sequences of the gp130/gp138 family are much more highly diverged between the species than for the vast majority of other related genes. ${ }^{11}$ The low amino acid sequence conservation, together with predicted high $\mathrm{N}$-glycan density but poor position conservation, suggests that a primary function of gp130 family members is to present a spectrum of $\mathrm{N}$-glycans at the cell surface. The glycan heterogeneity at specific sites is suggestive of a greater importance for contributing to the general glycocalyx $x^{10}$ at the cell surface than providing protein- or domain-specific functions for gp130. Recent evidence that the spectrum of $\mathrm{N}$-glycans expressed by $D$. purpureum overlaps little with that of $D$. discoideum ${ }^{11}$ is consistent with species-specific functions for the postulated N-glycan shroud, which correlates with species segregation in cell mixtures and cell level differences in kin selection that have been noted. ${ }^{62,63}$

The high degree of similarity of N-glycans among eukaryotes has its origin in the conservation of the structure of the lipid-linked $\mathrm{Glc}_{3} \mathrm{Man}_{9} \mathrm{GlcNAc}_{2}$ - precursor, which is involved in nascent protein folding, quality control, and ERAD in the rER. ${ }^{64}$ Like most organisms, Dictyostelium, a nonwalled amoeba, imparts its own species-specific modifications, here in the form of limited mannose-processing, intersecting and/ or bisecting GlcNAcs, peripheral $\mathrm{MePO}_{4}$ and $\mathrm{SO}_{4}$, and periph- 
Table 5. Identification of s-gp130 Glycopeptides

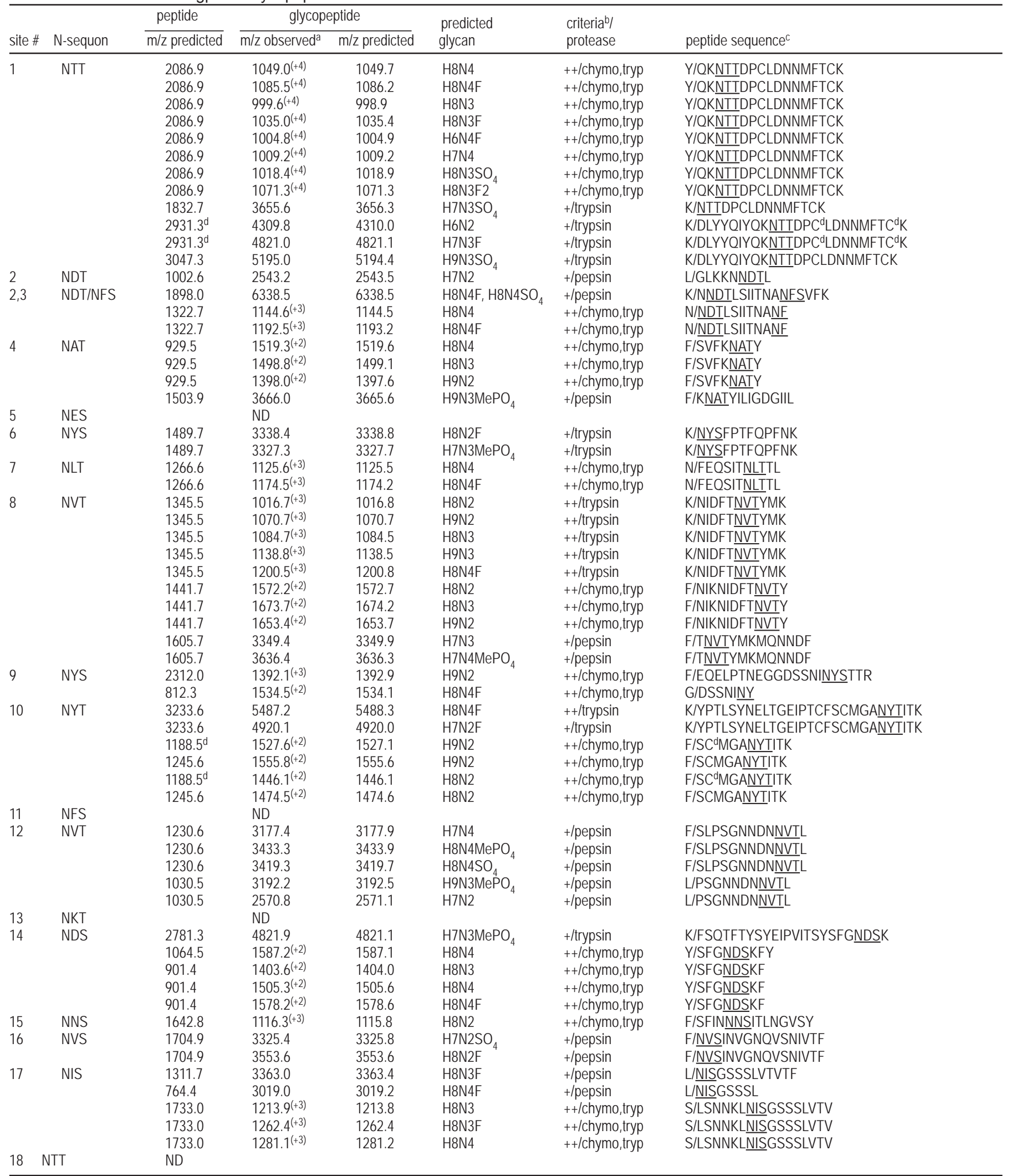

a. Ions are $[\mathrm{M}+\mathrm{H}]^{+}$except as indicated, and multicharged ions are multiprotonated; singly charged ions are from MALDI- experiments and multicharged ions are from QSTAR Elite (tryptic digests) or LTQ XL (all other) experiments; ND, not detected.

b. ++, high confidence assignment; tryptic glycopeptides: mass match, tryptic peptide seen after PNGase F digestion, MS/MS detected glycan oxonium and peptide ions; tryptic/chymotryptic glycopeptides: mass match, MS/MS detected [peptide+GlcNAc] ion and confirmed reported glycan; and coelution with other glycoforms in LC-MS +, midlevel confidence assignment; tryptic glycopeptides: mass match, peptide seen after PNGase F digestion; peptic glycopeptides: mass match, peptide seen after PNGase A digestion (no MS/MS confirmation).

c. Slash indicates peptide $\mathrm{N}$-terminal cleavage site; $\mathrm{N}$-sequon is bolded.

d. Except as noted by this superscript, Cys residues were alkylated with iodoacetamide. 
Table 6. Pairwise Protein Sequence and N-Sequon Comparisons of gp130 to its D. discoideum and D. pupureum Homologs ${ }^{\mathrm{a}}$

\begin{tabular}{|c|c|c|c|c|c|c|}
\hline species & common name & gene model $^{\mathrm{b}}$ & $\begin{array}{c}\text { number of } \\
\text { residues }\end{array}$ & $\%$ similarity/identity ${ }^{c}$ & $\begin{array}{c}\text { total } \\
\mathrm{N} \text {-sequons }\end{array}$ & $\begin{array}{l}\text { shared with } \\
\text { gp130 }\end{array}$ \\
\hline \multirow[t]{11}{*}{ D. discoideum } & \multirow[t]{8}{*}{ gp130 } & DDB0214937 & 768 & $100 / 100$ & 18 & 18 \\
\hline & & DDB0232382 & 582 & $48 / 40$ & 11 & 2 \\
\hline & & DDB0232386 & 755 & $44 / 36$ & 4 & 0 \\
\hline & & DDB0232388 & 753 & $44 / 36$ & 15 & 1 \\
\hline & & DDB0232393 & 764 & $43 / 34$ & 17 & 3 \\
\hline & & DDB0232379 & 707 & $40 / 33$ & 17 & 4 \\
\hline & & DDB0232389 & 880 & $39 / 33$ & 31 & 8 \\
\hline & & DDB0238839 & 681 & $38 / 30$ & 9 & 1 \\
\hline & gp138A & DDB0219938 & 730 & $42 / 35$ & 18 & 4 \\
\hline & gp138B & DDB0191447 & 734 & $42 / 35$ & 16 & 4 \\
\hline & gp138C & DDB0201648 & 746 & $40 / 34$ & 18 & 3 \\
\hline \multirow{2}{*}{ D. purpureum } & & DPU_G0071400 & 621 & $37 / 31$ & 3 & 0 \\
\hline & gp138? & DPU_G0063388 & 887 & $41 / 33$ & 20 & 1 \\
\hline
\end{tabular}

a. Inclusion criteria: $\geq 500$ amino acids, $\geq 28 \%$ similarity.

b. D. discoideum gene models from dictybase.org, and $D$ purpureum models are from dictybase (DPU numbers) or DOE Joint Genome Institute (genome.jgi-psf.org/Dicpu1/Dicpu1.download.html).

c. Percentage similarities and identities to Dd-gp130 were generated using the GAP routine of the GCG program.

eral and core a3-fucosylation. This study confirms the occurrence of these previously described glycans on a high abundance cell surface protein, and reveals that site heterogeneity is as extensive in this amoeba as it is in higher animals. ${ }^{65}$ It is remarkable that simple variants of high-mannose N-glycans are as suitable for cellular life in soils around the world as they are for stem cells (whose N-glycome approaches 50\% high mannose content) residing in the tissue beds of multicellular organisms. ${ }^{66,67}$ Future studies are needed to address how specializations of the high-mannose amoeba glycans as defined here for gp130 and more broadly for total N-glycans, influence intraspecific, interspecific and predator-prey interactions of social amoebae in their native habitats.

\section{Abbreviations}

$2 \mathrm{AB}, 2$-aminobenzamide

$\mathrm{ACN}$, acetonitrile

CID, collision-induced dissociation

Con A, Concanavalin A

ESI-QTOF, electrospray ionization-quadrupole time-of-flight mass spectrometry

Fuc, l-fucose (pyranose form)

GlcNAc, $N$-acetyl-d-glucosamine (pyranose)

GPI, glycophosphatidylinositol

H8N4, a glycan species with a composition of 8 Hex and 4 HexNAc residues

HexNAc, $N$-acetylhexosamine

HPAEC, high $\mathrm{pH}$ anion exchange chromatography

HPLC, high pressure liquid chromatography

$\mathrm{mAb}$, monoclonal antibody

MALDI-TOF/TOF-MS, matrix-assisted laser desorption ionization time-of-flight (dual-stage) mass spectrometry

Man, d-mannose

PAD, pulsed amperometric detection

PNGase F, peptide-N4-N-acetyl-beta-d-glucosaminyl)-asparagine amidase

$\mathrm{RP}$, reversed-phase; s-gp130, recombinant soluble form of gp130

DMSO, dimethylsulfoxide

TFA, trifluoroacetic acid

\section{Acknowledgment}

We thank Kathleen Williams for technical assistance with the initial purification of s-gp130. We also thank Dr. Michael Kinter (Oklahoma Medical Research Foundation) and Dr. Ken Jackson and Stephen Snow (OUHSC Molecular Biology and Protein Core Lab) for their assistance in the glycopeptide analyses. This research was supported by a Maude Hammond Fling Faculty Research Fellowship to CPC from the UNL Research Council, and support to the OCMG by the office of the Vice President for Research Office and the Department of Biochemistry and Molecular Biology at OUHSC.

Supporting Information, including Supplemental Table S1 and Supplemental Figures S1-S3, follows the References.

\section{References}

1. Chadwick, C. M.; Ellison, J. E.; Garrod, D. R. Dual role for Dictyostelium contact site B in phagocytosis and developmental size regulation Nature 1984, 307, 646- 647

2. Chadwick, C. C.; Thomas, E. W. Ligand binding properties of the sarcoplasmic reticulum $\left(\mathrm{Ca}^{2+}+\mathrm{Mg}^{2+}\right)$-ATPase labelled with N-cyclohexyl-N'-(4-dimethylamino-alpha-naphthyl)carbodiimide Biochim. Biophys. Acta 1984, 769, 291- 296

3. Chia, C. P. A 130-kDa plasma membrane glycoprotein involved in Dictyostelium phagocytosis Exp. Cell Res. 1996, 227, 182- 189

4. Chia, C. P.; Gomathinayagam, S.; Schmaltz, R. J.; Smoyer, L. K. Glycoprotein gp130 ofDictyostelium discoideum influences macropinocytosis and adhesion Mol. Biol. Cell 2005, 16, 2681- 2693

5. Aiba, K.; Fang, H.; Yamaguchi, N.; Tanaka, Y.; Urushihara, H. Isoforms of gp138, a cell-fusion related protein in Dictyostelium discoideum J. Biochem. 1997, 121, 238- 243

6. Fang, H.; Higa, M.; Suzuki, K.; Aiba, K.; Urushihara, H.; Yanagisawa, K. Molecular cloning and characterization of two genes encoding gp138, a cell surface glycoprotein involved in the sexual cell fusion of Dictyostelium discoideum Dev. Biol. 1993, 156, 201- 208

7. Fang, H.; Aiba, K.; Higa, M.; Urushihara, H.; Yanagisawa, K. 
Antisense RNA inactivation of gp138 gene expression results in repression of sexual cell fusion in Dictyostelium discoideum J. Cell Sci. 1993, 106, 785- 788

8. Hata, T.; Takahashi, M.; Tanaka, Y.; Urushihara, H. Total tetra knockout of GP138 multigene family implicated in cell interactions in Dictyostelium discoideum Gene 2001, 271, 33- 42

9. Hata, T.; Yamaguchi, N.; Tanaka, Y.; Urushihara, H. A new member of the GP138 multigene family implicated in cell interactions in Dictyostelium discoideum Cell Struct. Funct. 1999, 24, 123- 129

10. Dykstra, M. J.; Aldrich, H. C. Successful demonstration of an elusive cell coat in amebae J. Protozool. 1978, 25, 38- 41

11. Sucgang, R.; Kuo, A.; Tian, X.; Salerno, W.; Parikh, A.; Feasley, C. L.; Dalin, E.; Tu, H.; Huang, E.; Barry, K.; Lindquist, E.; Shapiro, H.; Bruce, D.; Schmutz, J.; Fey, P.; Gaudet, P.; Anjard, C.; Mohan, M. B.; Basu, S.; Bushmanova, Y.; van der Wel, H.; Katoh, M.; Coutinho, P. M.; Saito, T.; Elias, M.; Schaap, P.; Kay, R. R.; Henrissat, B.; Eichinger, L.; Rivero-Crespo, F.; Putnam, N. H.; West, C. M.; Loomis, W. F.; Chisholm, R.; Shaulsky, G.; Strassmann, J. E.; Queller, D. C.; Kuspa, A.; Grigoriev, I. Comparative genomics of the social amoebae Dictyostelium discoideum and Dictyostelium purpureum. 2010, submitted.

12. Boose, J. A.; Ziska, S. E.; Henderson, E. J. Defective intercellular cohesion in glycosylation mutants of Dictyostelium discoideum Dev. Genet. 1988, 9, 569- 578

13. Bozzaro, S.; Roseman, S. Adhesion of Dictyostelium discoideum cells to carbohydrates immobilized in polyacrylamide gels. II. Effect of D-glucoside derivatives on development J. Biol. Chem. 1983, 258, 13890- 13897

14. Loomis, W. F.; Wheeler, S. A.; Springer, W. R.; Barondes, S. H. Adhesion mutants of Dictyostelium discoideum lacking the saccharide determinant recognized by two adhesion-blocking monoclonal antibodies Dev. Biol. 1985, 109, 111- 117

15. Bozzaro, S. Cell surface carbohydrates and cell recognition in Dictyostelium Cell Differen. 1985, 17, 67- 82

16. Pang, T. L.; Wu, C. J.; Chen, P. A.; Weng, Y. L.; Chen, M. Y. Dictyostelium gnt15 encodes a protein with similarity to LARGE and plays an essential role in development Biochem. Biophys. Res. Commun. 2007, 360, 83- 89

17. Chia, C. P.; Luna, E. J. Phagocytosis in Dictyostelium discoideum is inhibited by antibodies directed primarily against common carbohydrate epitopes of a major cell- surface plasma membrane glycoprotein Exp. Cell Res. 1989, 181, 11- 26

18. Browning, D. D.; Lewis, K. E.; O'Day, D. H. Zygote giant cell differentiation in Dictyostelium discoideum: biochemical markers of specific stages of sexual development Biochem. Cell Biol. 1992, 70, 1200- 1208

19. Browning, D. D.; O’Day, D. H. Concanavalin A and wheat germ agglutinin binding glycoproteins associated with cell fusion and zygote differentiation in Dictyostelium discoideum: effects of calcium ions and tunicamycin on glycoprotein profiles Biochem. Cell Biol. 1991, 69, 282- 290

20. O'Day, D. H.; Rivera, J. Lectin binding and inhibition studies reveal the importance of D-glucose, D-mannose and N-acetylglucosamine during early sexual development of Dictyostelium discoideum Cell Differen. 1987, 20, 231- 237

21. Freeze, H. H. Dicytostelium discoideum glycoproteins: using a model system for organismic glycobiology. In New Comprehensive Biochemistry; Montreul, J.; Vliegenthart, J. F. G.; Schachter, H., Eds.; Elsevier: New York, 1998; Vol. 29B, pp 89- 121.

22. Schiller, B.; Hykollari, A.; Voglmeir, J.; Poltl, G.; Hummel, K.; Razzazi-Fazeli, E.; Geyer, R.; Wilson, I. B. H. Development of
Dictyostelium discoideum is associated with alteration of fucosylated N-glycan structures Biochem. J. 2009, 423, 41- 52

23. Zhang, Y.; Zhang, P.; West, C. M. A linking function for the cellulose-binding protein SP85 in the spore coat of Dictyostelium discoideum J. Cell Sci. 1999, 112, 4367- 4377

24. van der Wel, H.; Ercan, A.; West, C. M. The Skp1 prolyl hydroxylase from Dictyostelium is related to the hypoxia-inducible factor-alpha class of animal prolyl 4-hydroxylases J. Biol. Chem. 2005, 280, 14645- 14655

25. Huesgen, A.; Gerisch, G. Solubilized contact sites a from cell membranes of Dictyostelium discoideum FEBS Lett. 1975, 56, 46- 49

26. Wang, F.; Metcalf, T.; van der Wel, H.; West, C. M. Initiation of mucin-type O- glycosylation in Dictyostelium is homologous to the corresponding step in animals and is important for spore coat function J. Biol. Chem. 2003, 278, 51395- 51407

27. Shevchenko, A.; Wilm, M.; Vorm, O.; Mann, M. Mass spectrometric sequencing of proteins from silver-stained polyacrylaminde gels Anal. Chem. 1996, 68, 850- 858

28. Faye, L.; Gomord, V.; Fitchette-Laine, A. C.; Chrispeels, M. J. Affinity purification of antibodies specific for Asn-linked glycans containing alpha 1-->3 fucose or beta 1-->2 xylose Anal. Biochem. 1993, 209, 104- 108

29. Srikrishna, G.; Wang, L.; Freeze, H. H. Fucosebeta-1-P-Ser is a new type of glycosylation: using antibodies to identify a novel structure in Dictyostelium discoideum and study multiple types of fucosylation during growth and development Glycobiology 1998, 8, 799- 811

30. Hardy, M. R.; Townsend, R. R. High-pH anion-exchange chromatography of glycoprotein-derived carbohydrates Methods Enzymol. 1994, 230, 208- 225

31. Geyer, H.; Schmitt, S.; Wuhrer, M.; Geyer, R. Structural analysis of glycoconjugates by on-target enzymatic digestion and MALDI-TOF-MS Analyt. Chem. 1999, 71, 476- 482

32. Mechref, Y.; Novotny, M. Mass spectrometric mapping and sequencing of N-linked oligosaccharides derived from submicrogram amounts of glycoproteins Analyt. Chem. 1998, 3, 455- 463

33. Colangelo, J.; Orlando, R. On-target exoglycosidase digestions/MALDI-MS for determining the primary structures of carbohydrate chains Anal. Chem. 1999, 71, 1479- 1482

34. Bigge, J. C.; Patel, T. P.; Bruce, J. A.; Goulding, P. N.; Charles, S. M.; Parekh, R. B. Nonselective and efficient fluorescent labeling of glycans using 2-amino benzamide and anthranilic acid Anal. Biochem. 1995, 230, 229- 238

35. Kang, P.; Mechref, Y.; Novotny, M. V. High-throughput solidphase permethylation of glycans prior to mass spectrometry Rapid Commun. Mass Spectrom. 2008, 22, 721- 734

36. Lei, M.; Mechref, Y.; Novotny, M. V. Structural analysis of sulfated glycans by sequential double-permethylation using methyl iodide and deuteromethyl iodide J. Am. Soc. Mass Spectrom. 2009, 20, 1660- 1671

37. Dell, A.; Chalabi, S.; Easton, R. L.; Haslam, S. M.; Sutton-Smith, M.; Patankar, M. S.; Lattanzio, F.; Panico, M.; Morris, H. R.; Clark, G. F. Murine and human zona pellucida 3 derived from mouse eggs express identical O-glycans Proc. Natl. Acad. Sci. U.S.A. 2003, 100, 15631- 15636

38. Kang, P.; Mechref, Y.; Klouckova, I.; Novotny, M. V. Solidphase permethylation of glycans for mass spectrometric analysis Rapid Commun. Mass Spectrom. 2005, 19, 3421- 3428

39. Babu, P.; North, S. J.; Jang-Lee, J.; Chalabi, S.; Mackerness, K.; Stowell, S. R.; Cummings, R. D.; Rankin, S.; Dell, A.; Haslam, 
S. M. Structural characterisation of neutrophil glycans by ultra sensitive mass spectrometric glycomics methodology Glycoconj. J. 2008, 26, 975- 986

40. Huang, Y.; Mechref, Y.; Novotny, M. V. Microscale nonreductive release of O-linked glycans for subsequent analysis through MALDI mass spectrometry and capillary electrophoresis Anal. Chem. 2001, 73, 6063- 6069

41. Makino, Y.; Omichi, K.; Hase, S. Analysis of oligosaccharide structures from the reducing end terminal by combining partial acid hydrolysis and a two-dimensional sugar map Anal. Biochem. 1998, 264, 172- 179

42. Gonzalez-Yanes, B.; Mandell, R. B.; Girard, M.; Henry, S.; Aparicio, O.; Gritzali, M.; Brown, R. D., Jr.; Erdos, G. W.; West, C. M. The spore coat of a fucosylation mutant in Dictyostelium discoideum Dev. Biol. 1989, 133, 576- 587

43. Aparicio, J. G.; Erdos, G. W.; West, C. M. Spore coat is altered in modB glycosylation mutants of Dictyostelium discoideum J. Cell. Biochem. 1990, 42, 255- 266

44. Herscovics, A. Structure and function of Class I alpha 1,2-mannosidases involved in glycoprotein synthesis and endoplasmic reticulum quality control Biochimie 2001, 83, 757- 762

45. Couso, R.; van Halbeek, H.; Reinhold, V.; Kornfeld, S. The high mannose oligosaccharides of Dictyostelium discoideum glycoproteins contain a novel intersecting $\mathrm{N}$-acetylglucosamine residue J. Biol. Chem. 1987, 262, 4521- 4527

46. Faye, L.; Johnson, K. D.; Chrispeels, M. J. Oligosaccharide side chains of glycoproteinsthat remain in the high-mannose form are not accessible to glycosidases Plant Physiol. 1986, 81, 206- 211

47. Sharkey, D. J.; Kornfeld, R. Developmental regulation of asparagine-linked oligosaccharide synthesis in Dictyostelium discoideum J. Biol. Chem. 1991, 266, 18485- 18497

48. Sharkey, D. J.; Kornfeld, R. Identification of an N-acetylglucosaminyltransferase in Dictyostelium discoideum that transfers an "intersecting" $\mathrm{N}$-acetylglucosamine residue tohigh mannose oligosaccharides J. Biol. Chem. 1989, 264, 10411- 10419

49. Domon, B.; Costello, C. E. A systematic nomenclature for carbohydrate fragmentations in FAB-MS/MS spectra of glycoconjugates Glycoconj. J. 1988, 5, 397- 409

50. Lei, M.; Mechref, Y.; Novotny, M. V. Structural analysis of sulfated glycans by sequential double-permethylation using methyl iodide and deuteromethyl iodide J. Am. Soc. Mass Spectrom. 2009, 20, 1660- 1671

51. Murakami, T.; Natsuka, S.; Nakakita, S.; Hase, S. Structure determination of a sulfated $\mathrm{N}$ - glycans, candidate for a precursor of the selectin ligand in bovine lung Glycoconj. J. 2007, 24, 195- 206

52. Song, X.; Lasanajak, Y.; Xia, B.; Smith, D. F.; Cummings, R. D. Fluorescent glycosylamides produced by microscale derivatization of free glycans for natural glycan microarrays ACS Chem. Biol. 2009, 4, 741- 750

53. Song, X.; Lasanajak, Y.; Olson, L. J.; Boonen, M.; Dahms, N. M.; Kornfeld, S.; Cummings, R. D.; Smith, D. F. Glycan microarray analysis of P-type lectins reveals distinct phospho- mannose glycan recognition J. Biol. Chem. 2009, 284, 35201- 35214
54. Freeze, H. H.; Wolgast, D. Structural analysis of N-linked oligosaccharides from glycoproteins secreted by Dictyostelium discoideum. Identification of mannose 6-sulfate J. Biol. Chem. 1986, 261, 127- 34

55. Freeze, H. H.; Hindsgaul, O.; Ichikawa, M. A novel pathway for phosphorylated oligosaccharide biosynthesis. Identification of an oligosaccharide-specific phosphate methyltransferase in Dictyostelium discoideum J. Biol. Chem. 1992, 267, 4431- 4439

56. Freeze, H. H.; Yeh, R.; Miller, A. L.; Kornfeld, S. Structural analysis of the asparagine-linked oligosaccharides from three lysosomal enzymes of Dictyostelium discoideum. Evidence for an unusual acid-stable phosphodiester J. Biol. Chem. 1983, 258, 14874- 14879

57. Ivatt, R. L.; Das, O. P.; Henderson, E. J.; Robbins, P. W. Glycoprotein biosynthesis in Dictyostelium discoideum: developmental regulation of the protein-linked glycans Cell 1984, 38, 561- 567

58. Tschursin, E.; Riley, G. R.; Henderson, E. J. Differential regulation of glycoprotein sulfation and fucosylation during growth of Dictyostelium discoideum Differentiation 1989, 40, 1- 9

59. West, C. M.; van der Wel, H.; Coutinho, P. M.; Henrissat, B. Glycosyltransferase genomics in Dictyostelium discoideum. In Dictyostelium Genomics; Loomis, W. F.; Kuspa, A., Eds.; Horizon Scientific Press: Norfolk, U.K., 2005; pp 235- 264.

60. GCG Sequence Analysis Software Program, 2001; Acclerys ( http://accelrys.com/, San Diego, CA).

61. Aiba, K.; Yanagisawa, K.; Urushihara, H. Distribution of gp138, a cell surface protein responsible for sexual cell fusion, among cellular slime moulds J. Gen. Microbiol. 1993, 139, 279- 285

62. Sternfeld, J. Evidence for differential cellular adhesion as the mechanism of sorting-out of various cellular slime mold species J. Embryol. Exp. Morphol. 1979, 53, 163- 178

63. Mehdiabadi, N. J.; Jack, C. N.; Farnham, T. T.; Platt, T. G.; Kalla, S. E.; Shaulsky, G.; Queller, D. C.; Strassmann, J. E. Social evolution: kin preference in a social microbe Nature 2006, $442,881-882$

64. Banerjee, S.; Vishwanath, P.; Cui, J.; Kelleher, D. J.; Gilmore, R.; Robbins, P. W.; Samuelson, J. The evolution of N-glycan-dependent endoplasmic reticulum quality control factors for glycoprotein folding and degradation Proc. Natl. Acad. Sci. U.S.A. 2007, 104, 11676- 11681

65. West, M. B.; Segu, Z.; Feasley, C. L.; Kang, P.; Klouckova, I.; Novotny, M.; West, C. M.; Mechref, Y.; Hanigan, M. $\mathrm{H}$. Analysis of site-specific glycosylation of renal and hepatic $\gamma$-glutamyltranspeptidase from normal human tissue. Submitted.

66. Alvarez-Manilla, G.; Warren, N. L.; Atwood, J. A.; Dalton, S.; Orlando, R.; Pierce, M. Glycoproteomic analysis of embryonic stem cells: identification of potential glycobiomarkers using lectin affinity chromatography of glycopeptides J. Proteome. Res. 2010, 9, 2062- 2075

67. Satomaa, T.; Heiskanen, A.; Mikkola, M.; Olsson, C.; Blomqvist, M.; Tiittanen, M.; Jaatinen, T.; Aitio, O.; Olonen, A.; Helin, J.; Hiltunen, J.; Natunen, J.; Tuuri, T.; Otonkoski, T.; Saarinen, J.; Laine, J. The N-glycome of human embryonic stem cells BMC Cell Biol. 2009, 10, 42 
Supplemental Table S1. Glycosylation site mapping of tryptic glycopeptides

\begin{tabular}{|c|c|c|c|c|c|c|c|}
\hline $\begin{array}{c}\text { Site } \\
\#\end{array}$ & N-Sequon & $\begin{array}{l}\text { Peptide } \\
\mathrm{m} / \mathrm{z} \\
\text { predicted }\end{array}$ & $\begin{array}{l}\text { PNGase } \\
\text { F-product } \\
\mathrm{m} / \mathrm{z} \\
\text { predicted }\end{array}$ & $\begin{array}{l}\text { PNGase F- } \\
\text { product } m / z \\
\text { observed }^{a, b}\end{array}$ & $\begin{array}{c}\text { Endo } \mathrm{H}- \\
\text { product } \\
\mathrm{m} / \mathrm{z} \\
\text { predicted }\end{array}$ & $\begin{array}{l}\text { Endo } \mathrm{H} \text { - } \\
\text { product } \mathrm{m} / \mathrm{z} \\
\text { observed }^{\mathrm{a}, \mathrm{b}}\end{array}$ & Tryptic Peptide \\
\hline 1 & NTT & 1830.7 & 1831.7 & 1831.7 & 2033.7 & 2033.8 & $\underline{\text { NTTDPCLDNNMFTCK }}$ \\
\hline $2 / 3$ & NDT/NFS & 1898.0 & $1899.9(2)$ & $1898.7(1)^{c}$ & $2101.0(1)$ & $2101.4(1)^{c}$ & NNDTLSIITNANFSVFK \\
\hline 4 & NAT & 3016.6 & 3017.6 & 3017.5 & 3219.6 & & NATYILIGDGIILDSSLFNTLPNFYNK \\
\hline 5 & NES & 7433 & 7434 & & 7636 & & $\begin{array}{l}\text { ASIYIYNESIPIINDIIIIINLNQVTFTFINVPIPSNIF } \\
\text { SGSIEV FNILGIGYGFSLPSLLPENVALK }\end{array}$ \\
\hline 6 & NYS & 1489.7 & 1490.7 & 1490.6 & 1692.7 & 1692.9 & 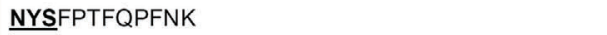 \\
\hline 7 & NLT & 4649.3 & 4650.3 & & 4852.3 & & 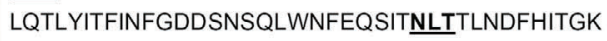 \\
\hline 8 & NVT & 1345.5 & 1346.5 & 1346.5 & 1548.5 & 1548.5 & NIDFT NVTYMK \\
\hline 9 & NYS & 3061.7 & 3062.7 & 3061.3 & 3264.7 & 3264.6 & MQNNDFEQELPTNEGGDSSNINYSTTR \\
\hline 10 & NYT & 3233.6 & 3234.6 & 3234.3 & 3436.6 & & YPTLSYNELTGEIPTCFSCMGANYTITK \\
\hline 11 & NFS & 2049.9 & 2050.9 & 2050.0 & 2252.9 & 2252.6 & SLPTNCETFNFSLDYNK \\
\hline 12 & NVT & 3647.1 & 3648.1 & 3648.7 & 3850.1 & & DFGWDFSLPSGNNDNVTLLITIPNNEITLSIPK \\
\hline 13 & NKT & 591.3 & 592.3 & & 794.3 & & GEGSNK \\
\hline 14 & NDS & 2781.3 & 2782.3 & 2781.2 & 2984.3 & 2984.8 & FSQTFTYSYEIPVITSYSFGNDSK \\
\hline 15 & NNS & 2683.3 & 2684.3 & & 2886.3 & 2886.4 & FYLNGNGFSFINNNSITLNGVSYK \\
\hline 16 & NVS & 6577.1 & 6578.1 & & 6780.1 & & $\begin{array}{l}\text { FIATADEQPSGNGYSSSSISFIDDGGEINNPIDSMLIGDE } \\
\text { FNVSINVGNQVSNIVTFYLYK }\end{array}$ \\
\hline 17 & NIS & 4033.1 & 4034.1 & 4034.1 & 4236.1 & & LNISGSSSLVTVTFDGEFGTTNSKIVFVSINGIQCIVK \\
\hline 18 & NTT & 2220.9 & 2221.9 & & 2423.9 & & TPTTTNTTSSEENGHDGSEQK \\
\hline
\end{tabular}

${ }^{a}$ all ions are $[\mathrm{M}+\mathrm{H}]^{+}$and are from MALDI-TOF studies

${ }^{b}$ red color indicates unmodified peptide detected; green color indicates modified peptide detected

${ }^{c}$ Modification of one of two sites observed 

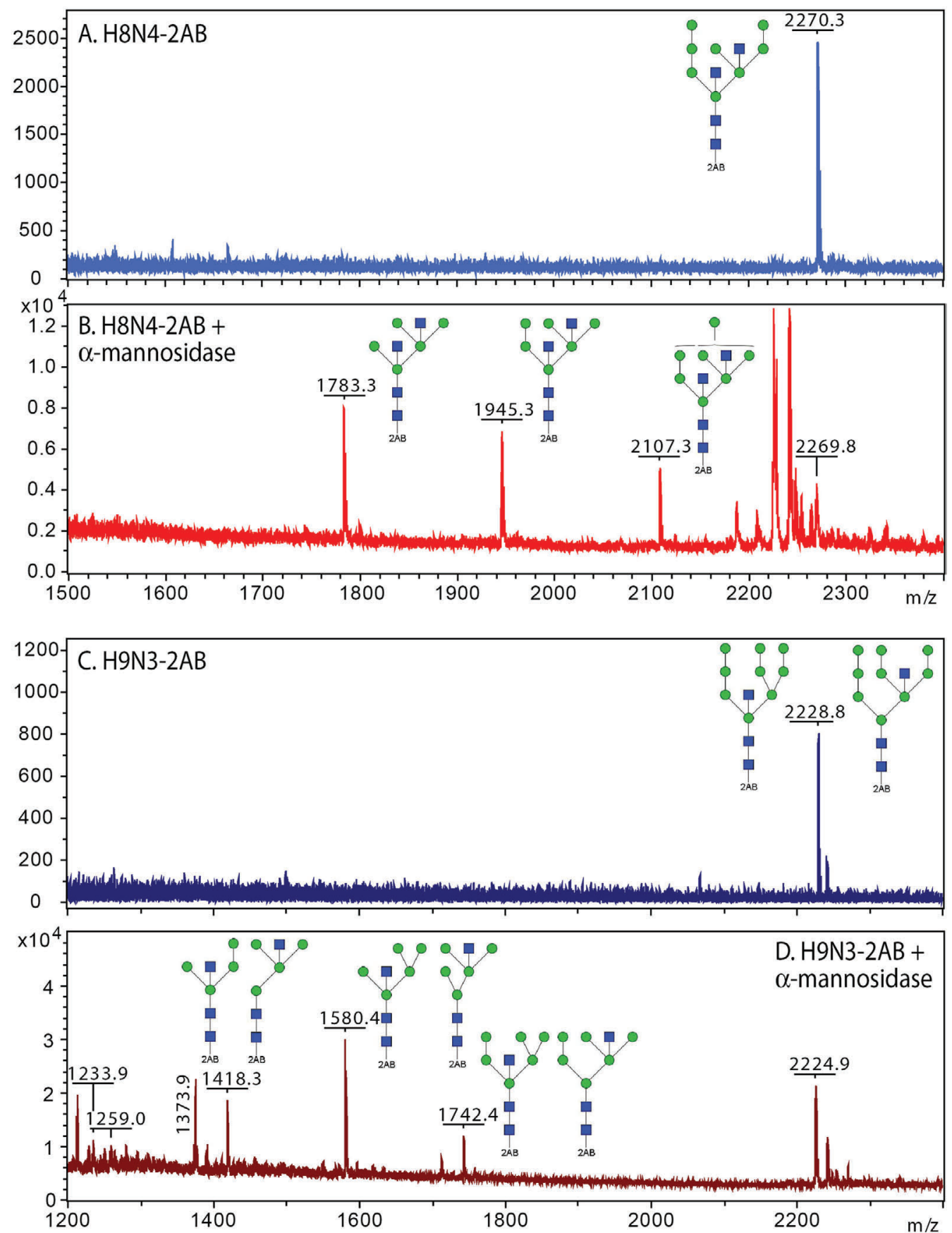

Supplemental Figure S1. Exoglycosidase digestion of s-gp130 glycans. Glycan composition and linkage positions of the GlcNAc residues were examined before and after exoglycosidase digestion of RP-HPLC purified H8N4-2AB and H9N3-2AB glycans by MALDI-TOF-MS (as in Figure 3B). A) Spectrum of H8N4-2AB with suspected intersecting and bisecting GlcNAcs before digestion. B) H8N4-2AB after Jack Bean a-mannosidase digestion. Three major products are observed (H7N4-2AB, H6N4-2AB, and H5N4-2AB). Most likely structures are depicted (see text). The glycan was unaffected by $\beta$-hexosaminidase digestion (data not shown), consistent with location of GlcNAcs at branch points that also protect neighboring mannose residues from a-mannosidase release. C) Spectrum of H9N3-2AB. Two likely configurations (intersecting and bisecting) are shown. D) a-mannosidase digestion of H9N3-2AB yielded three glycans (H6N3-2AB, H5N3-2AB, H4N3-2AB). H4N3$2 \mathrm{AB}$ is most consistent with an intersecting configuration, but both intersecting and bisecting possibilities are shown. Ions at $\mathrm{m} / \mathrm{z} 2224.9$, $1373.9,1259.0$, and 1233.9 represent non-dialyzable contaminants from the enzyme preparation (data not shown). All ions are singly charged $[\mathrm{M}+\mathrm{Na}]^{+}$ 


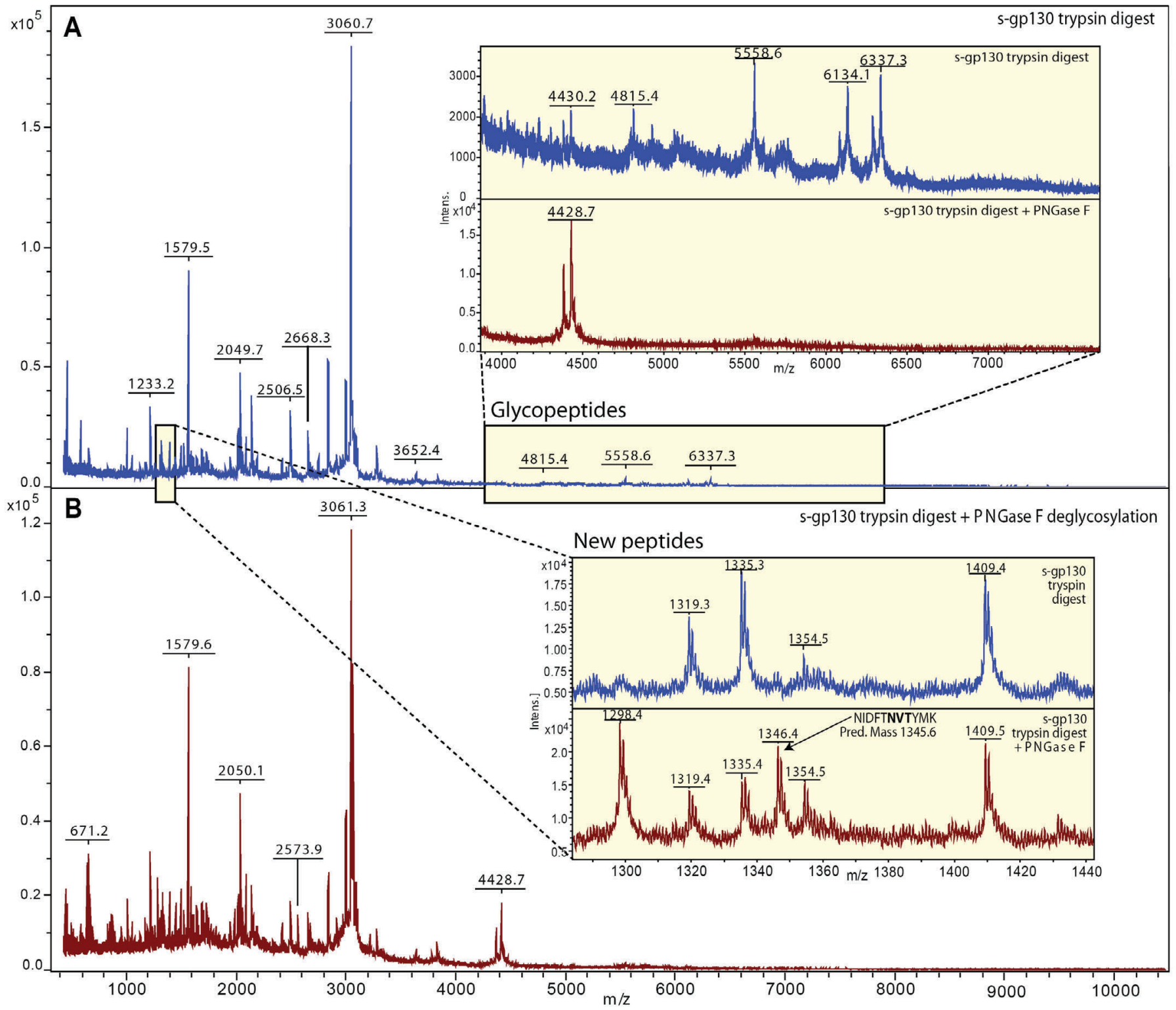

Supplemental Figure S2. MALDI-TOF-MS analysis in linear positive mode of s-gp130 tryptic peptides before (A) and after (B) PNGase F digestion. The upper inset (top panel) compares the high mass range containing PNGase F-sensitive peptides, and the lower inset (bottom panel) compares the low mass range showing novel peptides that appeared after PNGase F treatment. 

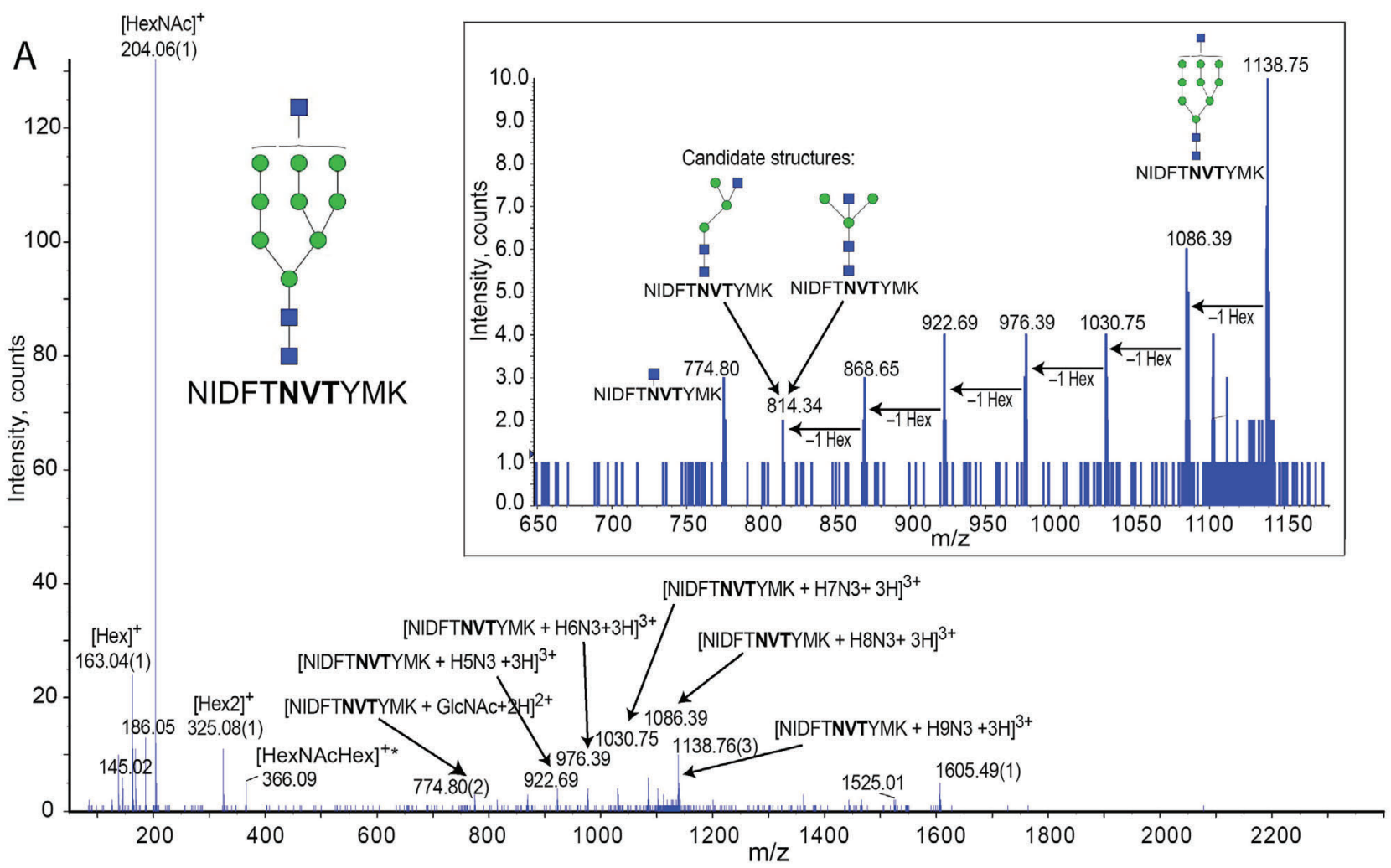

B
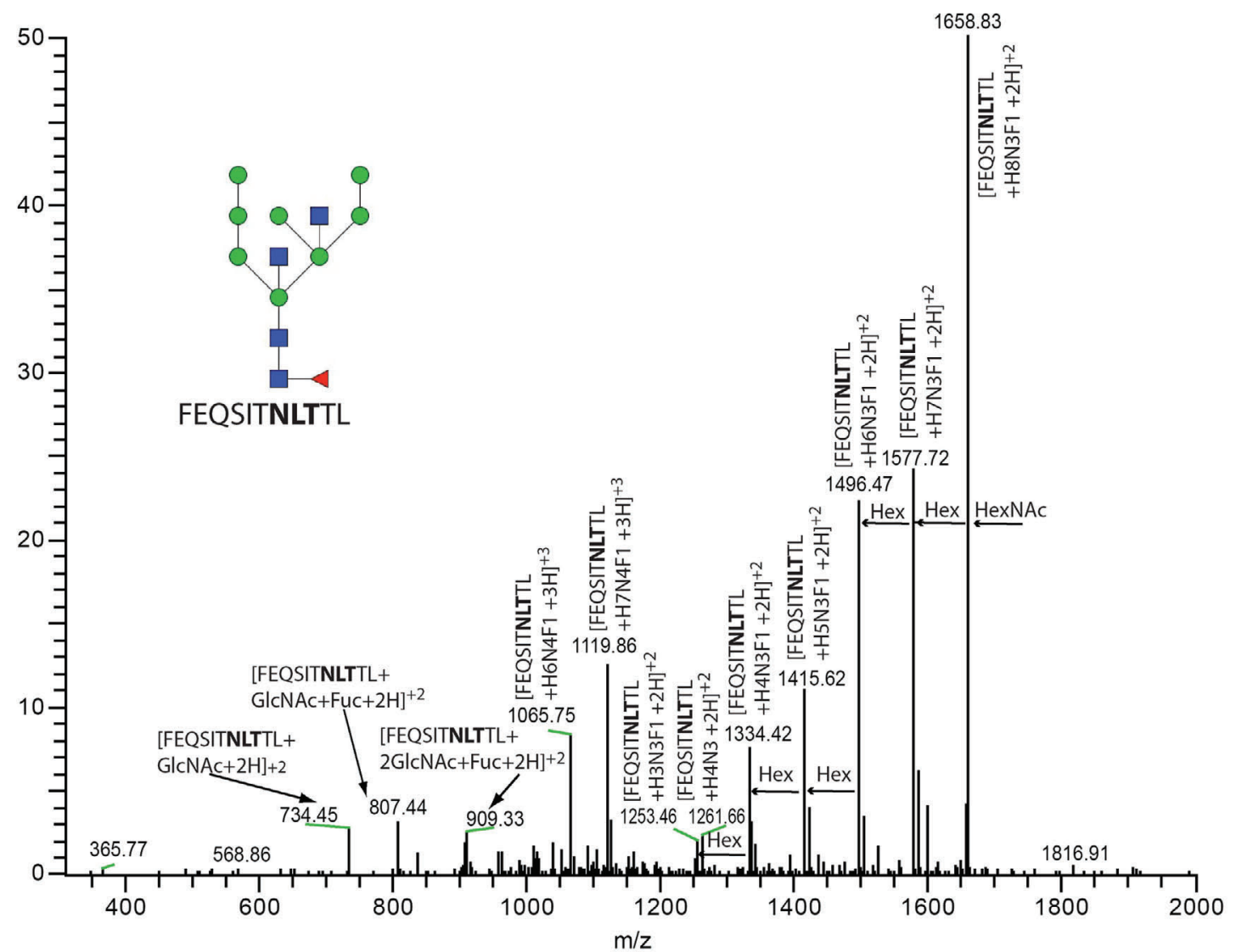

Supplemental Figure S3. MS/MS fragmentation of s-gp130 glycopeptides. A) A tryptic glycopeptide, identified as NIDFTNVTYMK+GlcNAc3Man9 $\left([\mathrm{M}+3 \mathrm{H}]^{+3}=\mathrm{m} / \mathrm{z}\right.$ 1138.76) containing site 8, was fragmented using CID in a QSTAR-Elite, which revealed the sequential loss of 6 mannose residues, the peptide+GlcNAc ion, and glycan oxonium ions in low mass range. B) a chymotryptic glycopeptide, identified as FEQSITNLTTL+H8N4F1 $\left([\mathrm{M}+3 \mathrm{H}]^{+3}=\mathrm{m} / \mathrm{z}\right.$ 1147.47) containing site 7, was fragmented by CID on a Thermo-Electron LTQ XL. The glycopeptide showed sequential losses of HexNAc, Hex, and dHex, depending on the charge state. dHex (Fuc) was linked to core GlcNAc based on presence of the [peptide+GlcNAc+Fuc] ion (m/z 807.44). 